\title{
Juan Pablo Izquierdo Fernández: Premio Nacional de Artes Musicales 2012. Perfil de su quehacer en Chile
}

\section{Juan Pablo Izquierdo-Fernández Winner of the 2012 National Art Prize in Music: a Profile of his Activity in Chile}

\author{
por \\ Carmen Peña Fuenzalida \\ Instituto de Música \\ Pontificia Universidad Católica de Chile \\ cpenaf@uc.cl
}

Esta comunicación presenta un perfil de la actividad desarrollada por Juan Pablo Izquierdo (1935) como director de orquesta en Chile. En el contexto de su permanencia en tres épocas -décadas del 60, 80 y a partir de 2008- se revisan selectivamente repertorios que le ha correspondido conducir y sus vínculos musicales con orquestas nacionales, especialmente la Orquesta Sinfónica de Chile, la Orquesta Filarmónica de Santiago y la Orquesta de Cámara de Chile, junto con recuperar comentarios de la crítica.

Palabras clave: Juan Pablo Izquierdo, orquestas de cámara chilenas, directores de orquesta, Premio Nacional de Arte, Orquesta Sinfónica de Chile, Orquesta de Cámara de Chile, Orquesta Filarmónica de Santiago.

This article presents a profile of the activity of Juan Pablo Izquierdo (1935) as an orchestral conductor in Chile considering three periods. The first two periods correspond with the decades of the 1960's and 1980's whereas the third period starts in the year 2008. A sample of the musical repertoire that he has conducted in Chile is analyzed along with his musical ties with national orchestras, in particular the Orquesta Sinfonica de Chile, the Orquesta Filarmónica de Santiago and the Orquesta de Cámara de Chile. Published reviews of his concerts in Chile are considered as part of the analysis.

Key words: Juan Pablo Izquierdo, Chilean chamber orchestras, orchestral conductors, National Art Prize, Orquesta Sinfónica de Chile, Orquesta Filarmónica de Santiago, Orquesta de Cámara de Chile.

\section{INTRODUCCIÓN ${ }^{1}$}

La figura de Juan Pablo Izquierdo (1935) es ampliamente conocida y reconocida tanto en el país como en el extranjero. Con una carrera artística que bordea los

1 Agradezco muy sinceramente la colaboración y apoyo que me prestaron para la elaboración de este trabajo al Dr. Luis Merino y a la señora Nancy Sattler, director y asistente de la RMCh respectivamente, a Giovanna Caruso, a Magdalena del Pedregal y Loreto Góngora, del Centro de Documentación de las Artes Escénicas (DAE) del Teatro Municipal.

Revista Musical Chilena, Año LXVII, julio-diciembre, 2013, N²20, pp. 20-51 
50 años, ha conducido distintas orquestas del mundo y su permanencia en Chile se ha circunscrito a periodos determinados. Radicado actualmente en el país ejerce como director titular de la Orquesta de Cámara de Chile. Los méritos de su productiva labor fueron reconocidos con el Premio Nacional de Artes Musicales 2012, como el tercero de los directores que recibe este galardón, junto con Víctor Tevah en 1980 y Fernando Rosas en $2006^{2}$.

Posiblemente, los aspectos más difundidos de los inicios de su carrera son los estudios musicales efectuados con los compositores Juan Orrego Salas, Carlos Botto y Juan Allende Blin, su partida a Alemania a perfeccionarse con el director Hermann Scherchen durante tres años, o la obtención del Premio Dimitri Mitropoulos (1966). Fue este el momento en que, en la práctica, Izquierdo comenzó a perfilarse con una fructífera proyección internacional. Sin embargo, no dejó de visitar Chile ya fuera como invitado a conciertos en temporadas o bien, como se verá en este sucinto perfil, para asumir la titularidad en orquestas nacionales.

La memoria es frágil y fragmentaria; con facilidad se olvidan logros o contribuciones. Hay oficios o profesiones cuyos productos o resultados permanecen en el tiempo; la arquitectura, pintura, escultura, por ejemplo. Pero la música, aquella que se escucha en vivo, en el concierto, y que completa esa tradicional cadena entre el creador y el público, se evapora si no es registrada. Ese es el sino de la gran mayoría de los intérpretes. Por tal razón en este trabajo se ha querido dejar constancia de una selectiva muestra de conciertos y obras abordadas por Juan Pablo Izquierdo, los que pueden aportar y acercar al lector a una dimensión más específica de su trabajo en el país.

En grandes líneas, su quehacer en Chile puede dividirse en tres etapas: sus inicios durante la década del sesenta, la época de titularidad en la Orquesta Filarmónica de Santiago, durante los años ochenta y su regreso a partir de 2008, también como director titular, pero esta vez de la Orquesta de Cámara de Chile, cargo que mantiene hasta la actualidad.

\section{DE LA COMPOSICIÓN A LA DIRECCIÓN ORQUESTAL}

Juan Pablo Izquierdo se inició en el oficio de director a comienzos de 1960, período especialmente nutrido en conciertos, ópera y ballet, gracias al amplio plan de difusión musical promovido e implementado por el Instituto de Extensión Musical de la Universidad de Chile, al que se sumó un creciente impulso y desarrollo de la actividad coral y de orquestas que, paulatinamente, se consolidó e involucró finalmente al sistema universitario en su totalidad. Tal es el caso, por ejemplo, de la creación en 1955 de la entonces Orquesta Filarmónica de Chile, con Juan Matteucci a la cabeza, la Orquesta Sinfónica de la Universidad de Concepción, iniciada por Wilfried Yunge en 1952 e integrada a dicha Universidad en 1958, la Orquesta de Cámara de la Universidad Católica de Valparaíso y la Orquesta de Cámara de la Universidad Católica de Chile, ambas fundadas por Fernando Rosas en 1960 y

2 Cf. Merino 1980 y Peña 2007. 
1964, respectivamente, o la novedosa Orquesta Juvenil fundada por Jorge Peña Hen en 1964 en La Serena, por mencionar solo algunos cuerpos instrumentales. Los estrenos, tanto de música contemporánea chilena y extranjera encontraron en ellas un lugar de privilegio, al igual que obras del repertorio paradigmático universal, junto con abrir espacios a los jóvenes intérpretes.

Pero los inicios de Juan Pablo Izquierdo en la música no fueron en la dirección orquestal, sino que en la composición, como recuerda en sus memorias Juan Orrego Salas ${ }^{3}$, maestro con el cual ha mantenido estrecho contacto hasta el día de hoy:

"En la distancia de más de seis décadas, en nuestra casa de la calle San Jorge en Santiago, revivo la figura del ángel barroco de Juan Pablo Izquierdo el día que llegó acompañado de su padre a contratarme unas clases particulares de composición. Los bosquejos que me presentó en nuestra primera reunión correspondían a los de su celestial apariencia: extensas melodías sobre estáticos pedales, ocasionalmente dobladas en cuartas y quintas abiertas, especies de 'organum' de la temprana polifonía. Juan Pablo era tímido para explicar sus ideas y a cuanto yo le sugería él respondía con un calmado movimiento de cabeza que a veces me dejaba en la duda si era afirmativo o negativo. No me parece que su trabajo en composición se haya prolongado por mucho tiempo y no acierto a establecer cuándo su interés por la dirección de orquesta comenzó a manifestarse, pero no olvido que en ese aspecto su desarrollo fue muy rápido y brillante. A su talento y perceptibilidad se debió, sin duda, el progreso inicial de su carrera y enseguida el valioso aporte del maestro Hermann Scherchen en Winterthur, a quien se dirigió para completar su formación".

Ciertamente el paso a la dirección orquestal fue definitivo luego de su experiencia en Alemania con Hermann Scherchen. Así, en 1960 y compartiendo con Ricardo Kistler, Armando Carvajal y Agustín Cullell, todos jóvenes en el oficio, participó en el cuarto concierto -y sus repeticiones en distintos teatros- de una Temporada de Primavera de la Orquesta Sinfónica de Chile, efectuado en el Teatro Hollywood $^{4}$. El programa incluyó la Primera Sinfonía op. 21 en Do mayor de Ludwig van Beethoven, Siete cantos al amor y a la muerte para tenor y orquesta de cuerdas, op. 8 -con Hernán Würth como solista- de Carlos Botto, la primera audición de Grotesca de Marcelo Morel, para finalizar con el poema sinfónico Los preludios de Franz Liszt. Al juzgar su actuación el crítico y musicólogo Samuel Claro Valdés escribió en La Nación: "Pese a su juventud, Izquierdo posee sólidos conocimientos y preparación básica de indiscutible mérito que bien pudieron apreciarse en su primera presentación como director de orquesta 5 ".

A partir de entonces y hasta la obtención del primer premio del Concurso Internacional Dimitri Mitropoulos para jóvenes directores -1966- dirigió la Orquesta Sinfónica de Chile, fue invitado a la Orquesta Filarmónica y luego se desempeñó como asistente de su director titular, Juan Matteucci, además de

\footnotetext{
3 Orrego Salas 2005: 127.

4 S/A 1960: 117-120.

5 S/A 1960: 119.
} 
ejercer el cargo de director del entonces Departamento de Música de la Pontificia Universidad Católica de Chile -1961-1963- en el que también actuó como director de orquesta en diferentes programas de las temporadas (Véjar 2001).

Pero volviendo a sus inicios en la dirección orquestal, no es de extrañar que luego de ese auspicioso primer concierto sus horizontes se ampliaran en el medio nacional y, junto a conciertos, varios con primeras audiciones de obras chilenas, estrenara óperas y ballet. Tal es el caso, por ejemplo, de la ópera La Sugestión de Pablo Garrido, estreno absoluto efectuado el 18 de octubre de 1961 en el Teatro Municipal. Con la soprano Matilde Broders y el barítono Rubén de Lorena como intérpretes, junto al Octeto de la Orquesta Filarmónica de Chile, bajo la dirección de Juan Pablo Izquierdo, la presentación fue evaluada como de "alta categoría", lo que comprobaba "que en Chile se puede hacer ópera moderna con dignidad, eficiencia y buen gusto 6 ".

De igual forma, el 8 de noviembre de ese mismo año, con el Ballet de Arte Moderno estrenó en el Teatro Municipal Impulso, con música de El umbral del sueño (1951) de Juan Orrego Salas, coreografía y libreto de Octavio Cintolesi y escenografía y trajes de Emilio Hermansen. Según se registra en Revista Musical Chilena ${ }^{7}$ :

"La música interpretada por la Orquesta Filarmónica, bajo la batuta de Juan Pablo Izquierdo, muy apropiada para ser bailada, contrastaba penosamente con la coreografía. No obstante, Cintolesi logró momentos aislados de hermoso plasticismo. Muy bueno el decorado e iluminación de Emilio Hennansen. La gama de colorido de los trajes no nos pareció igualmente feliz".

Como Director Asistente de Juan Matteucci participó en programas gratuitos de difusión cultural en poblaciones y parques de la Orquesta Filarmónica de Chile, en la Temporada Lírica de 1961 del Teatro Municipal ${ }^{8}$ y, en 1962, en los conciertos programados por el Departamento de Música de la Universidad Católica, efectuados en el Salón de Honor de esa casa de estudios. En estos últimos, ya se desempeñaba como director de dicho Departamento y dirigió atractivos programas con primeras audiciones, bien recibidas por la crítica. Así, en un concierto de obras de cámara, aparte del estreno en Chile del Quinteto de vientos, de Domingo Santa Cruz op. 33 (1960), dirigió el Octeto para instrumentos de viento de Igor Stravinsky, Cuatro piezas para clarinete y piano de Alban Berg y Octandre de Edgard Varèse. La apreciación de un crítico, suscrita por $R M C h$, es elocuente ${ }^{9}$ :

"si la interpretación de Strawinsky fue buena, aquella de Varèse puede calificarse de sobresaliente, llena de vigor y nitidez. Juan Pablo Izquierdo y el grupo de músicos bajo su dirección extrajeron de la compleja partitura un caudal sonoro, ante cuya sacudida nadie permaneció indiferente".

\footnotetext{
6 S/A 1961c: 88-89.

7 S/A 1961c: 91.

8 S/A 1961a: 80; S/A 1961b: 116.

9 S/A 1962: 211.
} 
Tan elogioso como el anterior fue el programa del 23 de julio de 1962, que consignó el Cuarteto $\mathrm{N}^{\circ} 2$ op. 10, de Arnold Schönberg, el estreno de Soliloquios para ocho solistas, de León Schidlowsky ${ }^{10}$, obra que -según se informa- se repitió al principio de la segunda parte, y Tres poemas de Mallarmé, de Maurice Ravel, en la voz de la soprano Clara Oyuela, acompañada por Juan Bravo y Alberto Harms (flautas), Juan Correa y Sebastián Acuña (clarinete), Rudi Lehman (piano) y el Cuarteto Santiago. Carlos Riesco estimó este concierto "como el más atrayente de la presente temporada. La jerarquía de interpretación alcanzada en esta ocasión fue sobresaliente, y de ello puede enorgullecerse el Departamento de Música y especialmente su director, Juan Pablo Izquierdo" 11.

Como parte de la difusión del Departamento de Música de la Universidad Católica, no menos importante fue el resultado de un seminario de ópera que ofreció -en septiembre- en la sala Camilo Henríquez cuatro funciones de la Historia de un marinero (Le pauvre matelot), de Darius Milhaud, con traducción de Federico Heinlein y El retablo de Maese Pedro, de Manuel de Falla. El conjunto instrumental estuvo bajo la dirección de Izquierdo y se señala que "la presentación de estas óperas constituyó un acontecimiento de importancia en la vida musical santiaguina y fueron muy elogiosamente comentadas por toda la crítica ${ }^{12 " . ~ A d e m a ́ s ~-e n ~ n o v i e m-~}$ bre de 1962-Izquierdo condujo la Cantata $N^{\circ} 80 \mathrm{de}$ Bach, acompañado por solistas y la Orquesta Interuniversitaria de Valparaíso ${ }^{13}$ y, en otro ámbito, como informa Riesco (1963: 11-12), formó parte del jurado de selección del Octavo Festival de Música Chilena, en calidad de miembro elegido por los concursantes, junto con Carlos Botto, representante de la H. Junta Directiva del Instituto de Extensión Musical; Víctor Tevah, director de la Orquesta Sinfónica de Chile; Agustín Cullell, representante de la Comisión de Estímulo a la Creación Musical; y Carlos Riesco, miembro elegido por los concursantes de festivales anteriores.

Según se puede observar, en el lapso de dos años, el repertorio interpretado por Juan Pablo Izquierdo se presenta como sumamente variado, característica que se ha mantenido en el tiempo como atestiguan otros conciertos y temporadas según él mismo se ha encargado de hacerlo notar, como se verá más adelante. Aparte de las temporadas oficiales en Santiago, dirigió en provincias, incluyendo, en varias ocasiones, conciertos educacionales. Este último rasgo lo mantiene hasta la actualidad como director titular de la Orquesta de Cámara de Chile según lo demuestra su reciente participación en "Conciertos para la familia", ofrecidos en julio de 2013 junto a la Orquesta Sinfónica ${ }^{14}$.

A partir de 1963 la agenda de Izquierdo comenzó a llenarse paulatinamente con conciertos de temporadas en las cuales participaron tanto directores nacionales

10 Según Grebe (1968: 46, 50) esta obra fue encargada por Carlos Riesco y está dedicada a Juan Pablo Izquierdo.

11 S/A 1962: 212.

12 S/A 1962: 212.

$13 \mathrm{~S} / \mathrm{A}$ 1962: 212

14 S/A. 2013, emol, jueves 18 de julio. Disponible en http://www.emol.com/noticias/magazine/2013/07/18/609713/juan-pablo-izquierdo-se-pone-al-mando-de-la-sinfonica.html [consulta $23 / 10 / 2013]$. 
como extranjeros. La XXII Temporada de la Orquesta Sinfónica de Chile demuestra muy bien la variedad de repertorio y el alto nivel de los directores. En ella dirigieron Víctor Tevah, de regreso como director titular luego de cinco años de ausencia, Hermann Scherchen y Volker Wangenheim, en tres ocasiones cada uno, además de Izquierdo, representando "a la nueva generación de directores nacionales".

El sexto concierto -16 de junio- incluyó la Suite $\mathrm{N}^{\circ} 1$ en Do mayor de J. S. Bach, Seis piezas para orquesta Op. 6 de Anton Webern, el Concierto $\mathrm{N}^{\circ} 18$ para piano y orquesta K. V. 456 de Wolfgang Amadeus Mozart, con Rudolf Lehmann como solista, y Bolero de Maurice Ravel. Comentado en RMCh, como un concierto "sobresaliente", se destacó su "inteligencia, profunda musicalidad, versatilidad, conocimiento a fondo de las partituras, sobriedad, claridad y dominio de la masa orquestal lo destacan como uno de los grandes directores del futuro"15. El segundo concierto bajo su mano, correspondiente al séptimo de la temporada -21 de junio de 1963- con un programa muy diferente y con elogios similares al anterior, destaca su rigurosidad en el estilo, sobriedad y certeza en el manejo orquestal, poniendo ante todo la obra por sobre el lucimiento personal ${ }^{16}$. En esa oportunidad, junto al estreno del Concierto $\mathrm{N}^{\circ} 1$ para violonchelo y orquesta, op. 107 de Dmitry Shostakovich, con Jorge Román como solista, se escuchó la Sinfonía en Sol Mayor $N^{\circ} 92$ "Oxford" de Joseph Haydn y la Sinfonía $\mathrm{N}^{\circ} 5$ en Do menor op. 67 de Ludwig van Beethoven.

Por otra parte, el Departamento de Música de la Pontificia Universidad Católica de Chile -bajo su dirección académica- contempló en su programación de 1963 dos obras inglesas: la "all-sung masque" Dido y Eneas de Henry Purcell y The Diary of a Madman, ópera de Humphrey Searle, cuya dirección musical estuvo a cargo de Frederick Fuller y Hernán Würth, con la dirección escénica de Eugenio Dittborn y Eugenio Guzmán y la dirección orquestal de Juan Pablo Izquierdo. A esto se agrega la primera audición de La historia del soldado de Stravinsky y de otras obras contemporáneas ${ }^{17}$.

El estreno en Chile de Dido y Eneas de Henry Purcell, que inauguró la Temporada de la Universidad Católica, fue considerado un aporte relevante a la cultura. Se destacó el esfuerzo mancomunado de un gran equipo de músicos con Izquierdo en la dirección musical de la obra "y cuya cohesión orquestal, coral y solística resultó verdaderamente eficaz”. Junto a él, se subraya la interpretación de la soprano Victoria Canale (Dido), el tenor Enrique del Solar (Eneas), las sopranos Carmen Barros y María Teresa Orrego, la mezzosoprano Inés Pinto, además del tenor Ignacio Bastarrica, lo mismo que el Cuarteto Santiago, con Federico Heinlein al clave, que se unió al conjunto instrumental, bajo la "certera" dirección de Izquierdo ${ }^{18}$. Algunas partes de esta obra fueron audicionadas en otros escenarios también bajo

15 S/A 1963b: 91.

16 S/A 1963c: 101.

17 S/A 1963a: 127. La información menciona a Pierrot lunaire de Arnold Schönberg, Intégrales, de Edgard Varèse, Cinco piezas para orquesta de cámara op. 10 de Anton Webern, Amatorias y De Profundis, de León Schidlowsky, Achorripsis de Iannis Xenakis, entre otras.

18 S/A 1963d: 109. 
su dirección. Tal es el caso de la Suite, en el Aula Magna de la Universidad Federico Santa María -24 de octubre de 1964- con la Orquesta de Cámara y el Coro de Cámara, ambos de la Universidad Católica ${ }^{19}$ y Fête en la ciudad de Valdivia, con la Orquesta de Cámara universitaria y la soprano Carmen Barros ${ }^{20}$.

Para Izquierdo, los conciertos se suceden en 1964. Con la Orquesta Sinfónica de Chile participó junto a Jorge Peña Hen, David Serendero y Víctor Tevah en aquellos al aire libre realizados durante enero, en la Temporada Oficial con sus repeticiones, en los conciertos de primavera, donde dirigió la primera audición del Concierto para clave en Mi bemol mayor de Johann Sebastian Bach, con Carla Hübner (solista) ${ }^{21}$, además de su participación en conciertos educacionales como aquellos realizados en enero de 1965 en el gimnasio Maccabi22.

Sobre su dirección en el duodécimo concierto de la Temporada Oficial de la Orquesta Sinfónica de Chile, que incluyó obras de Johann Sebastian Bach, Claude Debussy y la Sinfonía "La noche de cristal", de León Schidlowsky con el tenor Hanns Stein como solista. Pablo Garrido, en La Nación, señaló que fue un "acierto" confiarle la orquesta al joven director. En un programa que -según su óptica- presentaba 'escollos', mostró cualidades muy valoradas en el oficio como 'seriedad y hondura de estudio' logrando finalmente 'un concierto lleno de interés, verdaderamente memorable'23. No menos estimulante fue la apreciación de Carlos Riesco en $\mathrm{El}$ Diario Ilustrado sobre el siguiente concierto -el decimotercero del ciclo- en el cual se presentaron dos obras en primera audición: Cinco piezas para orquesta, op. 10 de Anton Webern y Concierto para viola, de Béla Bartók, con Manuel Díaz como solista, más la Sinfonía $\mathrm{N}^{\circ} 3$ de Beethoven. Junto con aludir al talento y avances del joven maestro, el crítico observa su madurez en la música contemporánea, el manejo orquestal y una "clara visión de lo que busca". En cuanto al resultado de la sinfonía beethoveniana consideró que ${ }^{24}$.

"La compenetración de los requerimientos idiomáticos se marcó de inmediato. Aún más, Izquierdo supo preparar los puntos culminantes de la composición mediante un adecuado control del fraseo temático y del realce instrumental, hasta alcanzar momentos de franco brillo expresivo".

En mayo de 1965 Izquierdo fue partícipe de un verdadero acontecimiento: el estreno de Cascanueces, de Pyotr Ilyich Tchaikovsky, por el Ballet Nacional Chileno junto a la Orquesta Sinfónica de Chile bajo su dirección. Esta versión, con coreografía de Charles Dickinson, basada en el original de Marius Petipa y Lev Ivanov, tuvo diversos comentarios en la prensa que -con mayor o menor grado

19 S/A 1964a: 158

20 S/A 1964a: 159.

21 S/A 1964c: 83.

22 S/A 1965a: 66.

23 S/A 1964b: 138. Esta versión de la Sinfonía "La noche de cristal" está grabada en el CD León Schidlowsky: obras sinfónicas. Compositores chilenos, volumen 4. ABA-SVR-17000-4. Santiago: SVR Producciones, Corporación Chilena de las Artes, Academia Chilena de Bellas Artes del Instituto de Chile, 2013.

24 S/A 1964c: 82. 
de aprobación- pusieron en relieve el desempeño del cuerpo de baile, la coreografía o el vestuario. Sin embargo, hubo un consenso en considerar el aporte del Ballet Nacional al medio cultural y la labor de Juan Pablo Izquierdo. Al respecto, en El Mercurio, Heinlein señaló que el director y la Orquesta Sinfónica de Chile "proporcionaron deleite con su acompañamiento musical de primera categoría", y Pasdechat, en El Diario Ilustrado comentó que su trabajo frente la Orquesta "probó que la preparación musical de un ballet conduce necesariamente a proporcionarle un apoyo vital, y que, en este sentido, la producción de 'Cascanueces' fue sobresaliente e impecable" 25 .

Seguido de este evento, nuevamente condujo en dos conciertos a la Orquesta Sinfónica en la XXIV Temporada de Invierno que, en esa ocasión, programó varias obras del siglo XX, incluyendo a creadores nacionales. En relación con el undécimo concierto -30 de julio de 1965- Pablo Garrido, en La Nación, se refirió expresamente al trabajo de Izquierdo y del cuerpo orquestal, a modo de ejemplo, en las Seis piezas para orquesta op. 6 de Anton Webern, señala ${ }^{26}$ :

“... Izquierdo está aquí, incuestionablemente, en su mejor dación. Justo es reconocerlo, como también lo será el decir que su instrumento -uno muy complejo y dúctil- le ha respondido con plasticismo y hasta con aquel pathos torturante que baña los distintos momentos de la audaz (jaún audaz!) partitura”.

El duodécimo concierto de esta misma temporada incluyó en primera audición Elegía a Macchu Picchu de Celso Garrido-Lecca, junto con obras de Johannes Brahms, Maurice Ravel y Claude Debussy. Las palabras de Federico Heinlein en El Mercurio fueron especialmente favorables para la interpretación de $\mathrm{El} \mathrm{mar}$, tres bocetos sinfónicos, escritos por el último de estos creadores ${ }^{27}$ :

"El compositor [Debussy] se habría alegrado de la interpretación que dieron el director y la orquesta a sus bocetos sinfónicos 'El mar'. No faltaron, por cierto, los valores atmosféricos, el tinte tornasolado, la riqueza de matiz. Pero el cuidado del detalle estuvo lejos de degenerar en delicuescencia, y la magnífica obra se armó con un vigor netamente beneficioso".

Dos años después -1967- la Elegía a Macchu Picchu de Garrido Lecca fue estrenada por Juan Pablo Izquierdo con la Orquesta Filarmónica de Nueva York. Según lo informa la RMCh, el crítico Harold G. Schonberg de The New York Times dijo que "Izquierdo dirigió la difícil partitura con seguridad impresionante" y, aunque era primera audición, "no cabía duda que el director dominaba la partitura, marcando los complicados ritmos con claridad y dominando en todo momento" 28.

A comienzos de 1966, mientras Juan Pablo Izquierdo se perfeccionaba en la dirección orquestal con una beca Guggenheim, obtuvo en Estados Unidos el primer premio del Concurso Internacional Dimitri Mitropoulos para jóvenes directores. La prensa de Santiago celebró este significativo logro de un compatriota y un

\footnotetext{
25 S/A 1965b: 96-97. ver en soporte papel.

26 S/A 1965c: 98.

27 S/A 1965c: 98-99.

28 S/A 1967: 94.
} 
artículo de El Mercurio informa que, antes de su partida, el Instituto de Extensión de la Universidad de Chile ya lo había contratado "para dirigir dos conciertos en la temporada sinfónica oficial del presente año" (Baccio Salvo 1966). Sin embargo, y pese a los compromisos que lo mantenían lejos del país, ese año y los que siguieron continuó presente en Chile en conciertos con la Orquesta Sinfónica y la Orquesta Filarmónica, entre otras.

A modo de ejemplo, su compromiso con la Orquesta Sinfónica de Chile se concretó en el cuarto y quinto concierto de la XXV Temporada Oficial, como los primeros que ofreció en Chile luego del mencionado galardón ${ }^{29}$. En el primer programa que incluyó la Sinfonía $\mathrm{N}^{\circ} 1$ en Do Mayor op. 21 de Ludwig van Beethoven, Equinoccio de Leni Alexander ${ }^{30}$ en primera audición, el Concierto para violonchelo y orquesta en La menor op. 129 de Robert Schumann, con Roberto González como solista, y La Valse de Ravel, Heinlein dijo:

“... cada año sentimos a Izquierdo más maduro y de mayor calibre. No se trata de un desarrollo brusco, sino de la evolución palmaria de virtudes que siempre lo han caracterizado. Destacamos de su entrega de la sinfonía, la sana estabilidad de los 'tempi', la ausencia de rebuscamiento, la clara estructuración de la forma en beneficio del fondo que oculta o representa. El brío, el clásico frescor de los movimientos iniciales, la tersura bruñida de Scherzo y Finales nos pusieron en contacto con un músico de fuste, maestro de su oficio, quien, mediante escuetas señales, logra extraer de la partitura todo su dinamismo inherente. En 'Equinoccio', estática creación de Leni Alexander, que cautiva el oído por su misterio y color más que por su organización rítmica o lineal perceptibles, el director obtuvo interesantes efectos tímbricos...”.

El quinto concierto fue dedicado a la memoria de Hermann Scherchen y tuvo por repertorio Historia del Nacimiento de Cristo de Heinrich Schütz, El sobreviviente de Varsovia de Arnold Schönberg, y Sinfonía $\mathrm{N}^{\circ} 3$ en Mi bemol (Heroica), op. 55 de Ludwig van Beethoven, esta última interpretada In memoriam del desaparecido maestro y director, mentor de Izquierdo e invitado en temporadas anteriores a la Orquesta. Federico Heinlein en su crítica a la obra de Schütz destacó la actuación de Hanns Stein y del Coro de Cámara de Valparaíso y el "entendimiento cabal, el sentimiento de actualidad inmediata" demostrado por Izquierdo, el cual también se reveló en la "excelente versión, que hubo de repetirse", de la obra de Schönberg, que "contó con la esmerada e impresionante labor de Hernán Würth y el Coro masculino del Conservatorio Nacional de Música, competentemente adiestrado por su directora Ruth Godoy". Sobre Beethoven, programado en honor de Scherchen, "recibió de la orquesta una ejecución digna del insigne director desaparecido. Izquierdo alcanza en ella un poderío soberano, una altura interpretativa maravillosa..." 31 .

29 Toda la información sobre estos conciertos se encuentra en S/A 1966a: 69-70.

30 Según Bustos (2007: 68) la obra se estrenó en 1962, en el Teatro Colón de Buenos Aires, Argentina, por la Orquesta Nacional, bajo la dirección de Jacques Bodmer y en Chile en 1966 por la Orquesta Sinfónica de Chile con Juan Pablo Izquierdo como director.

31 S/A 1966a: 69-70. 
Paralelamente, Juan Pablo Izquierdo fue invitado a dos conciertos de la XII Temporada Oficial de la Orquesta Filarmónica Municipal, efectuada en el Teatro Municipal y sus repeticiones en el Teatro Cariola. En ese ciclo, además de Agustín Cullell, su director titular, también dirigieron Julio Malaval (Argentina), Jacques Singer (Estados Unidos), David Serendero y Jorge Peña Hen (Chile), Choo-Hoey (Singapur), más Hiroyuki Iwaki con la Orquesta Sinfónica de Japón de la N.H.K., que ofreció dos conciertos fuera de abono ${ }^{32}$.

En el duodécimo concierto, Izquierdo condujo el poema sinfónico Redención de Cesar Franck, Piezas para orquesta de Eduardo Maturana, en primera audición, Concierto para viola de Béla Bartók, con Zoltan Fischer como solista, y la Sinfonía $\mathrm{N}^{\circ} 5$ (La Reforma) de Mendelssohn. El crítico Egmont, en El Siglo, señaló que "Izquierdo dio una sorpresa al público" con la obra de Mendelssohn por su interpretación con "vuelo, flexibilidad, intensidad expresiva y musicalidad", considerado que "fue lo mejor" de la jornada. Sobre Franck, estimó que el director "supo penetrar en su espiritualidad posromántica y mística, y que logró construir con éxito una obra fácilmente desarmable". En cuanto a la obra de Maturana, "tuvo en Juan Pablo Izquierdo un excelente intérprete" 33. En el concierto que siguió, junto con obras de Henry Purcell, Ludwig van Beethoven y Modest Mussorgsky se estrenó Llaqui de León Schidlowsky. La crítica de Federico Heinlein sobre la Suite de Dido y Eneas de Henry Purcell, señaló que Izquierdo condujo "con pulso firme" a las cuerdas de la Orquesta; mientras para el estreno en Chile de la elegía para orquesta Llaqui de León Schidlowsky se refiere más bien al compositor. Finalmente indica que Una noche en el Monte Calvo de Modest Mussorgsky, "acaso la interpretación más acabada de este concierto, fue testimonio del íntimo entendimiento que existe entre Izquierdo y la orquesta" 34 .

Ese año también participó, junto a Fernando Rosas y otros directores en la XV Temporada Oficial de la Orquesta de Cámara de la Universidad de Concepción, cuyo director titular era Wilfried Junge ${ }^{35}$.

Hasta finales de la década del sesenta Izquierdo estuvo presente en varias temporadas. Un breve recuento de algunos comentarios de prensa de Federico Heinlein dan cuenta, por una parte, de composiciones o estrenos de relevancia para la vida musical nacional y también de la solidez interpretativa alcanzada por Juan Pablo Izquierdo hasta entonces.

En un variado programa del noveno concierto de la XXVI Temporada Oficial de la Orquesta Sinfónica de Chile de 1967, efectuada en el Teatro Astor, el que entre otras obras consignó la Sinfonía $\mathrm{N}^{\circ} 1$ de Gustav Mahler, Heinlein ${ }^{36}$, como si intuyera que -en el futuro- este compositor sería uno de los frecuentemente

32 Toda la información sobre esta temporada corresponde a S/A 1966b: 77-81.

33 S/A 1966b: 80. Herrera (2003) indica que es la "versión para orquesta de cuerdas de las Diez micropiezas para cuarteto de cuerda, por encargo de Juan Pablo Izquierdo". Disponible en http:// www.scielo.cl/scielo.php?pid=s0716-27902003019900001\&script=sci_arttext

34 S/A, 1966b: 80. Esta versión de Llaqui está grabada en el CD León Schidlowsky: obras sinfónicas. Compositores chilenos, volumen 4. ABA-SVR-17000-4. Santiago: SVR Producciones, Corporación Chilena de las Artes, Academia Chilena de Bellas Artes del Instituto de Chile, 2013.

35 S/A 1966c: 93.

36 Heinlein 1967a: 59. 
escogidos por Izquierdo en sus programaciones, se explaya sobre sus cualidades interpretativas al señalar:

"Si algún oyente ha abrigado dudas en cuanto a la envergadura de Izquierdo, creemos que después de escucharle la primera sinfonía de Mahler debe de haber perdido toda incertidumbre al respecto. El joven chileno es un gran director, y podemos considerar un privilegio el hecho de tenerlo entre nosotros para esta serie de conciertos que está desarrollando con la Sinfónica. Plasma la música mahleriana con un entendimiento que no suelen demostrarlo sino los maestros centroeuropeos. Confiere carácter y perfil a la poesía y el éxtasis, el vigor rítmico y la desesperación. Logra una nitidez admirable, nos hace bailar y soñar. Presenta todos los efectos y efectismos de la partitura no como superficialidades sino como resultante de ocultas fuerzas anímicas, entregando una versión igualmente seductora por su elocuencia expresiva y la orgánica fusión de sonoridades orquestales".

"La Sinfónica de Chile tuvo uno de sus grandes días, desempeñándose de modo ejemplar en Gluck, Mozart y Mahler".

En lo que respecta al décimo concierto de la misma temporada, el crítico ${ }^{37}$ consideró que la Suite $\mathrm{N}^{\circ} 3$ en Re Mayor de Johann Sebastian Bach "fue una versión espléndida, no tomando en cuenta la fortuna cambiante de los sobreagudos en la primera trompeta", mientras que para el estreno de Laudes (I) de Celso Garrido-Lecca38 "los intérpretes lograron una atmósfera transparente en la que podía distinguirse cada detalle de la imaginativa y original instrumentación”. Sin embargo, los mayores elogios fueron para la Sinfonía en Re menor de César Franck:

"Izquierdo se acerca a las obras con un candor absoluto. Su pureza de ánimo parece prescindir voluntariamente de toda experiencia auditiva anterior, entablándose entre él y la partitura un diálogo fresco, nuevo, que 'viste de hermosura y luz no usada'. Nos entregó una Sinfonía de César Franck sin vetustez ni quejumbre, exenta, de pasajes blandengues o inanimados, cálida, lozana y radiante. Junto a la vena poética dio voz al titánico dramatismo del 'viejo ángel belga', como lo llamaba Debussy, recalcando con perfiles vívidos los diferentes planos sonoros. Hizo de esta creación un verdadero Concierto para orquesta, el que permitió a cada sector de la Sinfónica de Chile el máximo lucimiento en un enlace indiscutible de valores acústicos y espirituales”.

En el último concierto de la temporada 1967 -duodécimo-aparte de El retablo de Maese Pedro de Manuel de Falla, Izquierdo dirigió dos estrenos en Chile. Por una parte, la Misa en Fa, de Joaquim Lobo de Mezquita, obra colonial brasileña que había sido conducida por él ese mismo año en el marco del Quinto Festival de Primavera de Música Latinoamericana de la Universidad de Indiana ${ }^{39}$ y, por otra, Las bodas, "Escenas coreográficas rusas" de Igor Stravinsky. En cuanto a esta última, junto con recibir con entusiasmo un estreno esperado, Heinlein ${ }^{40}$ evaluó positivamente la interpretación:

37 Heinlein 1967b: 56.

38 Según el catálogo de Celso Garrido Lecca, de esta obra hay una grabación en casete por la Orquesta Sinfónica de Chile bajo la dirección de Izquierdo. Cf. Torres, Quezada Machiavello y Tello 2001: 29.

39 Grebe 1967: 107.

40 Heinlein 1967c: 63. 
"Las 'escenas coreográficas rusas' [...] fueron plasmadas por el magnífico director J. P. Izquierdo con todo el vigor y salvajismo requeridos. El maestro estableció entre los intérpretes un enlace sin conflictos. Los violentos contrastes dinámicos, los perturbadores ritmos cambiantes surgieron del modo más perfilado, destacándose los elementos orientales en esta partitura originalísima, aunque eminentemente eslava, que se cantó en idioma francés.

El Coro de Cámara de Valparaíso, preparado por Marco Dusi, se desempeñó en forma brillante. Una actuación de inusitado lucimiento cupo a las voces solistas. María Elena Guínez (soprano) fue incisiva a la par que flexible; Magda Mendoza (contralto), cálida y de registros hermosamente emparejados; Hernán Würth (tenor) exhibió un lirismo que, cuando las circunstancias lo exigían, tomaba caracteres de índole muy distinta; Jorge Algorta, visitante uruguayo de voz poderosa, se impuso con gallardía aun en los pasajes agudos más precarios. Los pianistas Óscar Gacitúa, Hilda Cabezas, Elvira Savi y Fernando Torm colaboraron de manera impecable, lo mismo que los demás instrumentistas de batería, cuyos nombres debieron haber figurado igualmente en la página central del programa impreso".

De 1968, año de pleno proceso de Reforma Universitaria, se ilustrarán los comentarios del crítico Federico Heinlein publicados en El Mercurio a tres de los cuatro conciertos dirigidos por Izquierdo en la XXVII Temporada Oficial de la Orquesta Sinfónica de Chile.

El primero de ellos, efectuado en el Teatro Astor -según era la costumbre-y repetido en el Teatro Municipal de Viña del Mar y el gimnasio Maccabi ${ }^{41}$, incluyó La pregunta sin respuesta de Charles Ives, Kadisch para violonchelo y orquesta de León Schidlowsky, con Eduardo Sienkiewicz como solista, y el Requiem de Wolfgang Amadeus Mozart. Sobre la obra de Ives, según el crítico, "el total comunica una rara sensación de suspenso, a la que los intérpretes supieron dar profundidad metafísica", mientras que en Schidlowsky: "la Sinfónica y su director resolvieron con aparente desembarazo todas las complejidades de la partitura, lo mismo que el excelente solista". El Requiem, por su parte, fue elogiado por la "formidable" interpretación, producto de "la voluntad plástica y el despierto sentido estructural de Izquierdo", lo mismo que el desempeño del Coro de la Universidad de Chile, que mostró "nitidez de ataques y cortes junto a una entrañable expresión finamente graduada” y el cuarteto de voces solistas -Lucia Gana (soprano), Carmen Luisa Letelier (contralto), Santiago Villablanca (tenor), Fernando Lara (barítono)- “cuya homogeneidad de escuela coadyuvó a su amalgamiento cabal". Concluye que "en suma, una versión inmejorable..." 42 .

41 Programa, noveno concierto, XXVII Temporada Oficial de la Orquesta Sinfónica de Chile, Universidad de Chile, Instituto de Extensión Musical, Teatro Astor, viernes 5 de julio, 1968; publicidad en El Mercurio, Santiago, viernes 5 de julio, 1968, p. 39 y sábado 6 de julio, 1968, p. 58.

42 Heinlein 1968a: 41. Esta versión de Kadisch está grabada en el CD León Schidlowsky: obras sinfónicas. Compositores chilenos, volumen 4. ABA-SVR-17000-4. Santiago: SVR Producciones, Corporación Chilena de las Artes, Academia Chilena de Bellas Artes del Instituto de Chile, 2013. 
La interpretación de La consagración de la primavera de Igor Stravinsky -undécimo concierto, del 19 de julio de 1968- para Federico Heinlein ${ }^{43}$ en general fue buena e "irradió magia y misterio",

"A pesar de la maraña instrumental el maestro supo mantener una diafanidad sonora de música de cámara exceptuando, naturalmente, aquellos pasajes brutales donde los timbres luchan como a mazazos". [...]

"Mientras que la mayoría de los directores suele hacer resaltar los vientos, Izquierdo parece dirigir una atención preferente a cuerdas y batería. Hubo instantes en los que el estruendo de la percusión hacía vanos los esfuerzos denodados de todos los demás ejecutantes. No cabe duda del efecto de esta versión que, junto con golpear las entrañas, tuvo vigor espiritual y mucha unidad de concepto. Sin entradas falsas que merezcan mención, la orquesta entregó un trabajo lúcido, de nivel técnico muy respetable”.

Finalmente, en el duodécimo concierto del viernes 26 de julio de $1968^{44}$, hubo cambio de programa respecto del original y tanto Las bodas de Igor Stravinsky como la cantata Actus Tragicus de Juan Sebastián Bach, debieron ser reemplazadas por enfermedad del bajo Jorge Algorta. No obstante, se interpretó un programa interesante, elogiado por Federico Heinlein ${ }^{45}$. Sobre la obra de Franck, Redención, opinó que "El maestro logró de la orquesta una considerable cultura sonora, caracterizándose su interpretación por la intensidad del sentimiento que en ella latía" y para el Concierto para la mano izquierda, de Ravel, con Fernando Torm como solista, argumentó que “...el joven pianista nacional supo hilar un discurso siempre conexo, creando, al mismo tiempo, climas de notable sugerencia”. En cuanto a las dos obras que coronaron el programa expresó:

"Izquierdo y un reducido conjunto de la Sinfónica tuvieron aciertos extraordinarios en 'Integrales' de Edgar Varèse, visión fascinante de un innovador, decidido a explorar comarcas acústicas ignotas... Después de la intrínseca riqueza de esta partitura de cámara, el genial 'Bolero’ de Ravel, habría parecido poco más que un truco mecánico, de no mediar la habilidad del director y sus músicos, quienes, con paso inexorable y obsesión monomaníaca, generaron un clímax de potencia electrizante".

Aunque la actividad de Juan Pablo Izquierdo se concentró en el extranjero, en los años siguientes continuó presente en temporadas realizadas en Santiago, especialmente de la Orquesta Sinfónica y la Orquesta Filarmónica. No obstante, igualmente que en Chile se informó sobre sus actuaciones y el repertorio que dirigió en el exterior que, como es sabido, con frecuencia incluyó a compositores nacionales y latinoamericanos.

En Chile, por ejemplo, con la Orquesta Filarmónica de Santiago dirigió en la temporada Oficial de 1970 un concierto dedicado a Franz Schubert, Johannes

43 Heinlein 1968b: 30.

44 Programa, duodécimo concierto, XXVII Temporada Oficial de la Orquesta Sinfónica de Chile e información de prensa, El Mercurio, Santiago, viernes 26 de julio, 1967, p. 37.

45 Heinlein 1968c: 55. 
Brahms y Félix Mendelssohn y otro con repertorio de Joseph Haydn, Sinfonía en Sol Mayor N 91, "Oxford", Xenakis, Metastaseis, Pithoprakta (obras interpretadas sin interrupciones), Ludwig van Beethoven, Concierto $\mathrm{N}^{\circ} 4$ en Sol mayor op. 58 para piano y orquesta, con Alicia de Larrocha como solista ${ }^{46}$. También estuvo en la XXX Temporada de Invierno de la Orquesta Sinfónica de Chile en 1971, e incluso -en julio- ofreció una audición en la ciudad de San Felipe a beneficio de los damnificados por el terremoto ocurrido ese mismo mes.

En 1972 nuevamente participó en la Temporada Oficial de la Orquesta Filarmónica de Santiago en un concierto en homenaje a Cesar Franck con ocasión del sesquicentenario de su nacimiento ${ }^{47}$ y en el Festival de Música Contemporánea de la Universidad Católica de Chile. En este último, junto a la Orquesta de Cámara de la Universidad condujo Noche transfigurada de Arnold Schönberg en homenaje al $20^{\circ}$ aniversario de la muerte del compositor, Sinfonía op. 21 de Anton Webern, Anaktoria, para quinteto de cuerdas, clarinete, corno y fagot de Iannis Xenakis, en primera audición en Chile, y Ionización para 12 percusionistas de Edgard Varèse ${ }^{48}$.

\section{LOS AÑOS EN LA ORQUESTA FILARMÓNICA DE SANTIAGO}

Luego del golpe de Estado la vida musical chilena fue especialmente compleja. Aparte de procurar restablecer confianzas y normalizar la propia actividad de conciertos, su rearticulación significó cambios, entre los cuales uno de fuerte repercusión fue el problema del autofinanciamiento. Un artículo publicado en El Mercurio, "Recuento de la temporada de conciertos $1980^{49 "}$, refleja esta y otras preocupaciones expresadas por quince músicos, críticos, profesores y personas responsables de las programaciones ${ }^{50}$.

En el balance, por una parte, se observó "ausencia casi total de estrenos de música chilena, la que ocupa un bajísimo porcentaje dentro de las programaciones" y, por la otra, limitaciones en el repertorio, principalmente "centrados en el periodo musical comprendido entre Bach y Debussy y tanto la música contemporánea como la anterior al periodo barroco están prácticamente marginadas" (p. E4). Como muestra el balance aporta que el 50\% de la Temporada de la Orquesta Filarmónica “está compuesta por piezas de Beethoven y Brahms, mientras

46 Centro DAE, Teatro Municipal. Disponible en http://www.centrodae.cl/wp_cdae/?cat=18\&bs =izquierdo\&x=7\&y=9\#resultados; http:/ / www.aliciadelarrocha.com/international-pianist/node $/ 24910$

47 Centro DAE, Teatro Municipal. Disponible en http://www.centrodae.cl/wp_cdae/?cat=18\&b $\mathrm{s}=$ izquierdo\&x=7\&y=9\#resultados

48 S/A 1972: 87.

49 S/A 1980: pp. E4-E5.

50 Algunos de ellos fueron: Ida Vivado (Asociación Nacional de Compositores), Juana Subercaseaux (Instituto de Música de la Universidad Católica de Chile), Víctor Tevah (Orquesta Sinfónica de Chile), Fernando Rosas (Agrupación Beethoven), Carlos Botto y Carlos Riesco (compositores), Federico Heinlein (compositor y crítico musical), Mary Ann Fones (cantante), Germán Domínguez (entonces director del Departamento de Extensión Cultural del Ministerio de Educación), Alejandro Gumucio (crítico) y Carlos Hevia (Teatro Municipal), entre otros (S/A 1980: pp. E4-E5). 
un porcentaje similar ocupan Mozart, Bach, Beethoven y Haydn en la programación total de la Agrupación Beethoven” (p. E4).

Las opiniones fueron diversas sobre los criterios de programación y la coordinación entre instituciones, el repertorio y la inclusión de compositores nacionales. Por ejemplo, se dice (sin identificar nombre) que "En la Filarmónica, la ausencia casi total de música chilena y contemporánea se debe a que 'dependemos mucho del autofinanciamiento, de manera que nuestra labor está centrada en el gusto del público'“ (p. E4). También se comenta que "la responsabilidad de la programación recae a veces en los directores y conjuntos extranjeros, quienes traen sus propios repertorios; en comisiones de estudio cuya composición no se explicita en forma bien definida; en el director estable del conjunto, o, en definitiva, en el propio responsable de la temporada..." (p. E4).

Sobre el financiamiento hubo consenso en considerar que era un tema difícil de resolver. El articulista señala: "El déficit presupuestario ronda cual verdugo decapitado de esperanzas e ilusiones, lo que ha obligado a los organizadores a buscar distintos cauces de financiamiento" (p. E5), vale decir, desde el aporte por concepto de ventas de entrada hasta el aporte de empresas privadas. Paralelamente, se analizó la proyección musical hacia las provincias - no del todo cubiertas- la escasa difusión de los medios de comunicación, y la necesidad de preocuparse por la educación musical.

En este marco y mientras Juan Pablo Izquierdo residía en Londres, en 1980 y 1981 dirigió en el Teatro Municipal en la Temporada de Conciertos de la Orquesta Filarmónica y también en la de la ópera. Sin embargo, su calidad de invitado pronto terminó.

A mediados de 1981, la Corporación Cultural de Santiago entró en un proceso de renovación. Se produjo cambio de directorio y el entonces alcalde de Santiago -Carlos Bombal- anunció una nueva política, orientada a la proyección hacia la comunidad. En ese contexto, a fines de 1981 la prensa anunció la celebración de los 125 años del Teatro Municipal y aires más frescos se avizoraron para la temporada 1982. Junto a novedades en infraestructura y la creación del Premio y Beca Corporación Cultural -como estímulo a figuras nacionales- se comunicó la visita de artistas de renombre en la ópera, ballet y conciertos. Tal es el caso de la soprano española Montserrat Caballé, el Ballet de Stuttgart y otras figuras de la danza, la Orquesta Filarmónica de Nueva York y su director Zubin Mehta, además del célebre Ramón Vinay, "uno de los mejores Otellos de todos los tiempos". Se esperaba una respuesta de Claudio Arrau para visitar Chile, lo cual recién se concretó en 1984. En cuanto a la Orquesta Filarmónica, la titularidad quedó en manos de Juan Pablo Izquierdo y Miguel Patrón Marchand como subdirector. Además se informó -para 1982- la presencia de Francisco Rettig, Max Valdés y, por primera vez, de Juan Felipe Orrego como directores invitados. También se anunció una temporada con dos abonos, más uno gratuito para estudiantes ${ }^{51}$.

Una selectiva muestra -y por lo tanto incompleta- de estrenos de creadores extranjeros y nacionales así como de programación de obras paradigmáticas

51 S/A 1981: p. E13. 
de esta etapa de la carrera de Juan Pablo Izquierdo dan cuenta, por un lado, de una labor innovadora en el repertorio del cuerpo orquestal y, por otro, de la visión amplia que imprimió durante su estadía como director titular. De este modo, junto con los compositores clásico-románticos paradigmáticos: Wolfgang Amadeus Mozart, Ludwig van Beethoven, Johannes Brahms, Félix Mendelssohn, Franz Liszt o Richard Wagner, para mencionar solamente algunos, las sinfonías de Gustav Mahler fueron invitadas infaltables, entre otras obras de este compositor austríaco, al igual que composiciones del siglo XX, muchas de ellas en calidad de estreno.

En la Temporada de 1983, bajo su dirección no solo se estrenó la Rapsodia para saxofón de Claude Debussy y Concierto para saxofón de Alexander Glazunov, ambas con Eugene Rousseau como solista, sino que -luego de veinte años- se repuso la Sinfonía $\mathrm{N}^{\circ} 5$ en Do Sostenido Menor de Gustav Mahler, obra que había sido anteriormente dirigida por Hermann Scherchen con la Orquesta Sinfónica de Chile. Izquierdo opinó que "la acogida del público fue excelente. A mi juicio el desempeño de la orquesta fue óptimo..." "52, mientras que Federico Heinlein luego de su análisis concluyó: "En resumen, una labor ardua más que respetable" 53 .

También, en un programa de 1983, compuesto por obras de Richard Wagner, Sergei Rachmaninoff e Igor Stravinsky, Izquierdo repuso la Elegía a Bartók, de Cirilo Vila. Esta obra, estrenada en 1981 por Francisco Rettig en las Semanas Musicales de Frutillar, ha sido dirigida por Izquierdo en ocasiones posteriores; a modo de ejemplo, en el Aula Magna de la Universidad Federico Santa María en 2009, con la Orquesta de Cámara de Chile, de la cual es titular en la actualidad ${ }^{54}$. Por otra parte, en el décimo concierto de abono 1983 de la Orquesta Filarmónica de Chile, último de la Temporada -28 y 30 de junio y sábado 2 de julio en la Catedral de Santiago, con entrada liberada, debido al éxito-, llevó al escenario la monumental Sinfonía N $^{\circ} 2$ en Do Menor de Gustav Mahler, junto a los solistas, el Coro Profesional y Lírico de la Corporación Cultural y el Coro del Departamento de Música de la Academia Superior de Ciencias Pedagógicas. Con una evaluación muy positiva, Heinlein dijo: "En resumen, un triunfo brillante de Izquierdo y sus músicos, estruendosamente celebrado por la concurrencia" 55 .

Para el año siguiente y con algunos traspiés por cambios de fechas y horarios a raíz de la implantación del "toque de queda", en el sexto concierto de la Temporada 1984 ofreció nuevamente a Gustav Mahler, esta vez la Sinfonía N $^{\circ} 3$ en Re menor. Reforzada con músicos de la Facultad de Artes de la Universidad de Chile ${ }^{56}$, más Carmen Luisa Letelier (contralto solista), el Coro Profesional de

52 S/A 1983a: p. C16.

53 Programa de concierto, Centro DAE, Teatro Municipal; Heinlein 1983a: p. C16.

54 Disponible en: http://noticias.universia.cl/vida-universitaria/noticia/2009/05/13/289053/ juan-pablo-izquierdo-dirige-obras-gustav-mahler-cirilo-vila-universidad-santa-maria.html [consulta 31 octubre 2013].

55 Programa de concierto, Centro DAE, Teatro Municipal; Heinlein 1983b: p. C11.

56 A los cuales la Corporación Cultural agradece en el programa de ese día. Cf. programa de concierto, Centro DAE, Teatro Municipal. 
Santiago (con el refuerzo de algunas invitadas) y el Coro de Niños del Santiago College -preparados por Jorge Klastornick y Cecilia Martorell, respectivamente-, tuvo una favorable crítica ${ }^{57}$.

Otra obra fundamental del repertorio universal -séptimo concierto de 1984coincidiendo con Semana Santa, fue La Pasión según San Juan de Johann Sebastian Bach, con la participación del Coro del Grupo Cámara Chile (director: Mario Baeza Gajardo) y los solistas Aldo Baldin (tenor), Carmen Luisa Letelier (contralto), Mario Solomonoff (bajo), Violaine Soublette (soprano) y J. Escobar (barítono). La presentación fue considerada como una "entrega memorable" de la obra ${ }^{58}$.

Un estreno para América Latina fue el Requiem de Guerra de Benjamin Britten en el decimocuarto concierto de 1984 . Al respecto la crítica señaló:

"Impecable el desempeño de la orquesta, lo mismo que aquel del conjunto de cámara capitaneado por Stefan Terc, cuyos solistas cumplieron tareas admirables [...]", al mismo tiempo que se destacó el papel del director en los siguientes términos: "Héroe máximo de la jornada fue Juan Pablo Izquierdo, quien con seguridad absoluta manejó el completo aparato y dio vida candente al mensaje de la obra" ${ }^{59}$.

Tanto en 1983 como en 1984 Juan Pablo Izquierdo organizó un Festival de Música Contemporánea. Sobre el primero, realizado el 3 y 12 de diciembre, la prensa anunció que, como organizador del evento, él seleccionó las obras participantes, que incluyeron "clásicos" (Igor Stravinsky, Edgard Varèse, Arnold Schönberg) y compositores chilenos (Guillermo Rifo, Alejandro Guarello, Cirilo Vila, Miguel Aguilar). La obra El sobreviviente de Varsovia, con el barítono Fernando Lara como narrador y el coro de 80 voces masculinas, dirigido por Waldo Aránguiz, se incluyó en ambos conciertos, advirtiéndose que serían más breves de lo habitual, "ya que se necesita dar aire al espectador de un programa de música nueva" 60 .

Las obras nacionales que figuraron en programa fueron Canto de Cirilo Vila ${ }^{61}$, Concierto para siete instrumentos de Miguel Aguilar, Sinfonietta de Alejandro Guarello y el estreno de Visiones nocturnas de Guillermo Rifo. Izquierdo señaló que por su espacio para la improvisación, la última de ellas "cada vez que se escucha, suena diferente", y en cuanto a la Sinfonietta de Alejandro Guarello, cabe decir que se trató de un estreno en Santiago ${ }^{62}$, ya que su primera audición se efectuó en febrero de 1981 bajo la dirección de Francisco Rettig63. Por su parte el Octeto e Historia del soldado de Igor Stravinsky, Intégrales de Edgard Varèse más la Sinfonía

57 Programa de concierto, Centro DAE, Teatro Municipal; Heinlein 1984a: p. C19.

58 Programa de concierto, Centro DAE, Teatro Municipal; Heinlein 1984b: p. C8.

59 Programa de concierto, Centro DAE, Teatro Municipal; Heinlein 1984d: p. C15.

60 Programa de concierto, Centro DAE, Teatro Municipal; S/A 1983b: p. C12.

61 No hay mayores especificaciones sobre esta obra. Es posible que se trate de Canto (1..., 2...), de 1968 [O-18], de acuerdo al catálogo, aunque allí aparece sin información de estreno. Cf. Torres 2005: 20.

62 Programa de concierto, Centro DAE, Teatro Municipal; S/A 1983 b: p. C12.

63 Disponible en: http://guarello.tripod.com/Orquesta.htm 
de cámara op. 9-B y la obra antes mencionada de Arnold Schönberg, completaron el Festival. En una evaluación global del evento, Federico Heinlein escribió ${ }^{64}$ :

"La excepcional faena del maestro titular J. P. Izquierdo fue un factor determinante de la categoría de este festival de música contemporánea. Sus indicaciones (tiempo, dinámica, intención), son nítidas a la vez que de suprema elegancia y funcionalidad. Qué placer observar cómo arma las estructuras y les extrae su más recóndita esencia”.

Un par de meses antes de la realización del Festival de Música Contemporánea de 1984 se anunció que Juan Pablo Izquierdo estaba absolutamente dedicado a la preparación del evento. Según Andrés Rodríguez, director artístico de la Corporación Cultural de Santiago, su expertise así lo ameritaba puesto que se trata de un festival "gigantesco", adelantando que, entre las obras, figuraba la Sinfonía Turangalila de Olivier Messiaen ${ }^{65}$. Poco después y ad portas del evento una nota de prensa informó que Izquierdo venía llegando de Europa, “donde cumplió una serie de compromisos y contrajo otros", como una grabación para la BBC de Londres que transmitiría a diferentes países europeos. Agrega que en junio de 1985, el maestro dirigirá "La des-creación del mundo" de Kagel en el Festival de Amsterdam"66.

Al igual que el Festival anterior, el programa de 1984 bajo su dirección contempló obras "clásicas" del siglo XX - Edgard Varése, Igor Stravinsky, Charles Ives, Béla Bartók-y otras más contemporáneas -Steve Reich, Mauricio Kagel-incluyendo -como siempre- música nacional que en este caso se trató del estreno de Los Heraldos Negros de León Schidlowsky ${ }^{67}$, compositor al cual Izquierdo ha interpretado en varias ocasiones, según se ha visto. Sin embargo, lo más promocionado fue el estreno de la Sinfonía Turangalila de Olivier Messiaen programada para la primera jornada del Festival. Fue propuesta por Izquierdo "por la magnitud espiritual que representa, porque es una de las obras más importantes de mediados de este siglo y porque necesita una gran orquesta y la Filarmónica se encuentra en muy buen pie para interpretarla ${ }^{68}$ ”. La apreciación de Federico Heinlein confirmó el buen resultado 69 :

"Héroe de la jornada, que se recordará en los anales del Teatro Municipal, Juan Pablo Izquierdo capitaneó el enorme superboeing musical, con una fascinación tan comprensible como evidente, haciendo aparecer simple lo complicado gracias a su fenomenal pericia técnica. La Filarmónica, [Jean François] Heisser [piano] y Jeanne Loriod [ondas Martenot] le respondieron admirablemente. Por largos minutos fueron aplaudidos todos los ejecutantes".

64 Programa de concierto, Centro DAE, Teatro Municipal; Heinlein 1983c: p. C10.

65 S/A 1984a: p. C12.

66 S/A 1984b: p. C12.

67 Programa de concierto, Centro DAE, Teatro Municipal; S/A 1984 c:p.C15; Heinlein 1984 a:p. C19; Según S/A 1999b:97, se estrenó esta obra por la Orquesta Sinfónica de Chile dirigida por Juan Pablo Izquierdo en el Teatro de la Universidad de Chile el 6 de agosto de 1999.

68 Quintana 1984: p. E4.

69 Programa de concierto, Centro DAE, Teatro Municipal; Heinlein 1984 e: p. C9. 
La visita de Claudio Arrau a Chile en 1984 no solo fue un acontecimiento para el país, sino también para Izquierdo. Su relación data de la época en que este último trabajó con Leonard Bernstein como asistente en la Orquesta Filarmónica de Nueva York. Según Izquierdo, a raíz de un encuentro que tuvo con Arrau con posterioridad a un concierto, comenzó su carrera en Europa, ya que él lo "introdujo en muchos círculos musicales”, pero además -dice Izquierdo- de sus conciertos "aprendía actitudes clave mirándolo trabajar"70.

En Chile, Arrau ofreció recitales y conciertos masivos con orquesta bajo la dirección de Víctor Tevah junto a la Orquesta Sinfónica de Chile y de Juan Pablo Izquierdo, con la Orquesta Filarmónica. La crítica destacó tanto las cualidades interpretativas del maestro como la de los cuerpos orquestales y sus directores. Mientras Tevah dirigió en la Catedral de Santiago, Izquierdo lo hizo en el Teatro Municipal, el 12 de mayo. Ambos conciertos fueron transmitidos por la Televisión Nacional, señal de Canal 7.

El repertorio con la Orquesta Filarmónica de Santiago bajo la conducción de Izquierdo estuvo conformado por dos obras cumbre: el Concierto $\mathrm{N}^{\circ} 5$ en Mi Bemol Mayor para piano y orquesta op. 73 "El Emperador" de Ludwig van Beethoven y el Concierto $\mathrm{N}^{\circ} 1$ en Re menor op. 15 para piano y orquesta de Johannes Brahms. Para Izquierdo, esa fue la primera vez que actuó con Claudio Arrau y la crítica no escatimó elogios. Federico Heinlein, en su comentario titulado "Regreso a la Patria: bienvenido, Claudio Arrau", escribió: "Emocionante a la vez que avasallador fue el regreso de Claudio Arrau", mientras para la interpretación de ambas obras expresó lo siguiente ${ }^{71}$ :

"En el Allegro inicial [Concierto $\mathrm{N}^{\circ} 5$ de Beethoven] la Orquesta Filarmónica, dirigida por J. P. Izquierdo, dio algunas señales de nerviosismo, más que comprensibles. Pronto desaparecieron los errores o crudezas y la ocasional falta de nitidez, para dar paso a sonoridades exquisitas en el movimiento central y notable perfil característico en el rondó concluyente".

"El titular del conjunto municipal se esmeró en secundar al célebre pianista del modo más solícito $[\ldots]$

"Infinitamente conmovedora fue la versión del Primer Concierto de Brahms, en la que Arrau, Izquierdo y la Filarmónica alcanzaron cumbres expresivas [...]”.

El año 1985 fue complejo. El terremoto de marzo obligó a evaluar y reparar los daños del Teatro Municipal y fue necesario cambiar de escenario para la Temporada. De este modo, y con los problemas acústicos que significó su traslado al Teatro Astor y al Cine Gran Palace (para el primer y segundo concierto respectivamente), Izquierdo y la Orquesta lograron llevar adelante la programación. El concierto de apertura incluyó Noche transfigurada de Arnold Schönberg y La canción de la Tierra de Gustav Mahler. Pese a los inconvenientes, la evaluación de Izquierdo fue positiva, ya que, por una parte, "el profesionalismo de los músicos hizo posible

70 Jurado 2010: 143.

71 Programa de concierto, Centro DAE, Teatro Municipal; Heinlein 1984c: p. C10. 
que en pocas horas se adaptaran en la mejor forma a la nueva sonoridad"72 y, por otra, la recepción del público fue muy buena.

Con un ciclo denominado "De Bach al presente" (300 años de continuidad) comenzó la celebración de los 300 años del nacimiento del músico alemán el año 1985. Con amplia visión del legado bachiano, los conciertos incluyeron obras de Wolfgang Amadeus Mozart, Félix Mendelssohn, Ludwig van Beethoven, Gustav Mahler, Arnold Schönberg y Alban Berg, entre otros, y por cierto del mismo Bach.

El segundo concierto de temporada de la Orquesta Filarmónica de Santiago, esta vez en el cine Gran Palace, con varias repeticiones, presentó El arte de la fuga de Johann Sebastian Bach en una versión orquestada por Izquierdo. La crítica elogió la buena acústica de la sala, la "habilidad" del director en su orquestación y el "clima" logrado por los músicos que "respondieron con profesionalismo ejemplar a las nítidas indicaciones de velocidad y dinámica"73. Otro programa del ciclo -correspondiente al sexto concierto- fue dedicado a la Sinfonía N $^{\circ} 3$ "Heroica" de Ludwig van Beethoven y la Sinfonía $\mathrm{N}^{\circ} 5$ "La Reforma" de Félix Mendelssohn. El alto nivel de la Orquesta y su director queda en evidencia en las palabras que introducen y cierran el minucioso comentario de Federico Heinlein: “¡Con qué gusto acompañó el auditorio del Teatro Municipal a Juan Pablo Izquierdo en su reedición de dos partituras que domina hasta el más ínfimo detalle!". "Pocas veces podrán oírse mejor interpretadas estas dos sinfonías"74.

También en el ciclo en honor a Bach, para el undécimo concierto se programó la Sinfonía $\mathrm{N}^{\circ}$ 6, de Gustav Mahler, y en el siguiente se incluyó un contundente corpus de obras: la transcripción orquestal de Arnold Schönberg para un Preludio y Fuga de Johann Sebastian Bach, Variaciones para orquesta, de Arnold Schönberg, y La consagración de la primavera de Igor Stravinsky. Finalmente, en el decimocuarto concierto de 1985 se interpretó en primera audición Giro de Alejandro Guarello, y Tres fragmentos de Wozzeck, de Alban Berg. Los tres conciertos mencionados tuvieron una crítica muy favorable, destacándose tanto la calidad y profesionalismo del cuerpo orquestal como el vigor, rigor y expresividad de Izquierdo ${ }^{75}$.

Ocho de los doce conciertos de la Temporada Oficial de la Orquesta Filarmónica de Santiago de 1986 -con sus repeticiones- estuvieron a cargo de Izquierdo. El ciclo contempló un vasto repertorio figurando, entre otras, Sinfonía N 1 "Titán”, de Gustav Mahler en el primer concierto; Stabat Mater de Giovanni Battista Pergolesi en el quinto concierto ${ }^{76}$; Sinfonía Turangalîla de Olivier Messiaen y el Concierto para violín de Alban Berg, con Jaime de la Jara como solista, en el décimo concierto; Requiem alemán op. 45 de Johannes Brahms en el duodécimo concierto ${ }^{77}$; más la obra chilena Preludios dramáticos de Domingo Santa Cruz en el segundo concierto.

72 Nota de prensa en El Mercurio, Santiago; S/A 1985: p. C11.

73 Programa de concierto, Biblioteca Nacional de Santiago; Heinlein 1985a: p. C15.

74 Programa de concierto, Biblioteca Nacional de Santiago; Heinlein 1985b: p. C11.

75 Programas de concierto, Biblioteca Nacional de Santiago; Heinlein 1985c:p.C11; Heinlein 1985 d:p.C9; Heinlein 1985 e: p. C14.

76 Programa de concierto, Centro DAE, Teatro Municipal; Heinlein 1986c: p. C17.

77 Programa de concierto, Centro DAE, Teatro Municipal; Heinlein 1986a: p. C14; Heinlein 1986d: p. C9; Heinlein 1986a: p. C14. 
Sobre esta última obra, el propio compositor, asistente al concierto, dijo: "No se puede hacer una ejecución mejor de mi obra", comentando además que "La Orquesta Filarmónica está excelente, magnífica. Yo la escucho todos los años y veo sus progresos. La dirección de Juan Pablo Izquierdo es de primera línea, como pocos"78.

Un concierto de esa temporada -noveno- que incluyó la Obertura trágica y el Concierto para piano $\mathrm{N}^{\circ} 2$, ambos de Johannes Brahms, más la Sinfonía $\mathrm{N}^{\circ} 5$ de Ludwig van Beethoven, ilustra y refleja bien los objetivos que orientan a Juan Pablo Izquierdo tanto entonces como actualmente sobre el trabajo con la orquesta y la programación, como él se encargó de señalar en una entrevista. Sobre el primer aspecto dijo ${ }^{79}$ :

"Son obras de gran dificultad y que requieren de un trabajo muy especial porque nunca deben tocarse como si fuera 'una vez más'. Entonces, hemos iniciado un tipo de trabajo como si fuera la primera vez que la tocáramos. He dividido la orquesta en distintas secciones y hemos ido estudiando lentamente, volviendo al texto original y dándonos cuenta de cómo a veces sin querer nos apartamos de él. El lenguaje de Beethoven es un lenguaje tan concentrado que requiere que cada uno de los más pequeños motivos tenga su propia significación...”

Por otra parte, en relación con el criterio de programación de ese concierto expresó:

"Siempre tengo la preocupación de que cada programa tenga una unidad en sí mismo, y, además, corresponda a un criterio general de la programación completa. No es una casualidad, por ejemplo, de que tengamos ahora a Brahms y Beethoven. Siempre me preocupo de que haya una unidad y en este caso particular, el parentesco entre ambos compositores, es decir, lo que Brahms le debe a Beethoven es tan enorme y tan reconocido por él y por la historia de la música, que creo que marchan muy bien juntos. Este trabajo de los pequeños motivos de que hablábamos antes también es una característica del lenguaje de Brahms. Y esa manera de redactar viene, sin duda, de Beethoven"”.

\section{AL MANDO DE LA ORQUESTA DE CÁMARA DE CHILE}

Entre 1990 y 2008 Juan Pablo Izquierdo se radicó en Estados Unidos, como Director de Estudios Orquestales en la Carnegie Mellon University School of Music, en Pittsburgh, Pennsylvania, según lo demuestra el artículo de Marilyn Taft Thomas, que se publica en este número de la Revista. No obstante y aunque mantuvo su actividad internacional, continuó vinculado con Chile. A modo de ejemplo, en 1990 creó la Orquesta Claudio Arrau, de la cual es su Director Musical; en 1998

78 Programa de concierto, Centro DAE, Teatro Municipal; S/A 1986a: p. C13; Heinlein 1986b: p. C13.

79 S/A 1986b: p. C13. 
fue galardonado por el Círculo de Críticos de Arte en el rubro música nacional ${ }^{80}$; en 1999 dirigió a la Orquesta de Cámara de Chile en la Temporada Internacional de Conciertos del Teatro Oriente de la Fundación Beethoven y fue invitado a la Temporada Oficial de la Orquesta Sinfónica de Chile en 1999. En el año 2000 dirigió a dicha Orquesta y, junto al Coro Sinfónico de la Universidad de Chile y la Camerata Vocal, realizó un concierto solidario por los damnificados de los temporales, organizado por la Federación de Estudiantes de la Universidad de Chile (FECH), el Centro de Alumnos de la Facultad de Artes y el Centro de Extensión de la Universidad de Chile ${ }^{81}$. El año 2005 recibió el Premio Municipal de Arte, mención música docta, otorgado por la Ilustre Municipalidad de Santiago ${ }^{82}$.

El nuevo milenio también trajo algunas reflexiones. En 2003, Juan Orrego Salas, recordando casos de músicos que han dejado Chile por diferentes razones, en su artículo "Exilio, ¿pérdida o provecho?" dice (2003:68):

"En el espacio de la dirección orquestal el caso de Juan Pablo Izquierdo constituye para Chile un alejamiento muy difícil de compensar, puesto que no sólo se trata de una personalidad musical apreciada en Europa, el Medio Oriente y América, donde se desempeña regularmente como director invitado, sino que de un eficaz educador de orquestas, y como director de la Sinfónica del Carnegie-Mellon de Pittsburgh, un excepcional promotor de la música contemporánea en sus conciertos y en grabaciones internacionalmente apreciadas. Las ausencias de Francisco Rettig y Patricio Cobos, en esta misma especialidad, merecen ser consideradas en razón de que, si bien ponen en relieve el nombre de Chile en el exterior, al mismo tiempo lo privan de las que podrían ser valiosas contribuciones a su vida musical. En esta capacidad hay que celebrar el regreso a Chile de Max Valdés y formular deseos de que perdure sirviéndolo”.

A partir de 2008 Juan Pablo Izquierdo inició una nueva etapa en Chile. Tras el fallecimiento de Fernando Rosas (2007) asumió como director titular de la Orquesta de Cámara de Chile del Consejo Nacional de la Cultura y las Artes, cargo que concilió con su rol de director de la cátedra de Estudios Orquestales -antes mencionada- en Pittsburgh.

La noticia tuvo eco e inmediatamente Izquierdo planteó algunos cambios como su interés por "el perfeccionamiento de la Orquesta y la ampliación del repertorio”. Con ello apuntaba a una mayor apertura hacia la música contemporánea, lo que incluía también la creación nacional, por una parte, y salir a otras localidades de Chile, idea que no pudo concretar mientras estuvo frente a la Orquesta Filarmónica (Cerda 2008).

Como es sabido, la Orquesta de Cámara de Chile, perteneciente al Consejo Nacional de la Cultura y las Artes, cubre un amplio espectro de auditores con sus temporadas de conciertos en Ñuñoa, Las Condes y Viña del Mar. Paralelamente, es una asidua invitada a las temporadas de conciertos de la Universidad Técnica

80 S/A 1999a. Disponible en http://dx.doi.org/10.4067/S0716-27901999019100009 [consulta $30 / 9 / 2013]$.

81 S/A 2000: 105.

82 S/A 2006: 100 . 
Federico Santa María, de la Fundación Beethoven y de la Corporación Cultural de Viña del Mar. Además realiza una importante labor de comunicación de la música mediante conciertos gratuitos, entre sus muchas actividades. Al igual que otras orquestas del país, también cuenta con directores invitados nacionales y extranjeros.

Desde su debut en la temporada del Teatro Municipal de Las Condes de 2008 con obras de Johann Sebastian Bach y Meditaciones de León Schidlowsky -compositores con los cuales Izquierdo tiene una enorme afinidad-con poca publicidad y muchas acciones ha tratado de llevar a cabo el proyecto que lo anima. Una breve muestra de algunos de los conciertos y obras que ha efectuado en diversos escenarios ilustra bien tales propósitos.

Ese mismo año 2008, en la Temporada de la Orquesta Sinfónica de la Universidad de Concepción, en el Teatro de la Universidad de Concepción, también dirigió Meditaciones, de León Schidlowsky. En Valparaíso, en un concierto Homenaje a Isidor Handler -17 de mayo-, la Orquesta de Cámara de Chile junto al Coro Sinfónico de la Universidad de Chile y solistas, bajo su dirección ofreció Cantata $N^{\circ} 131$ De lo profundo clamo a ti, Señory Cantata $N^{\circ} 140$ Despertad, nos llama la voz, ambas de Johann Sebastian Bach, junto a la obra de León Schidlowsky antes mencionada $^{83}$. En julio, en el marco de la Temporada Fernando Rosas 2008, con la Orquesta de Cámara de Chile en el Teatro Oriente condujo la Sinfonía No. 38 en Re M, KV 504, "Praga", de Wolfgang Amadeus Mozart, Sinfonía No. 1 en Do M. op. 2 de Ludwig van Beethoven y Canciones del caminante de Gustav Mahler (en versión para orquesta de cámara por Arnold Schönberg) con Patricio Sabaté (barítono) ${ }^{84}$. En noviembre, con un programa dedicado a Ludwig van Beethoven y otro en el cual incluyó la Sinfonía de cámara, op. 9 de Arnold Schönberg, estuvo en la Parroquia Santa Elena, como parte del concierto de la Temporada de la Orquesta de Cámara de Chile ${ }^{85}$, y en la Universidad Santa María ${ }^{86}$, respectivamente. Para el Día de la Música -22 de noviembre-, celebrado en la parroquia Nuestra Señora del Carmen, la Orquesta de Cámara de Chile dirigida por su titular incluyó Divertimento $\mathrm{N}^{\circ} 1$ de Roberto Falabella, obra que se repitió -26 del mismo mes- en el concierto de la temporada de la Corporación Cultural de Las Condes ${ }^{87}$.

Como es posible observar, la política de Juan Pablo Izquierdo de dar cabida a la música nacional ha estado presente desde el comienzo de su gestión y, hay que decirlo, en muchas oportunidades, logrando que una misma obra sea escuchada

83 S/A 2008a "Maestro Juan Pablo Izquierdo encabeza homenaje a Isidor Handler en Universidad Santa María”, 12 de mayo. Disponible en: http://noticias.universia.cl/vida-universitaria/ noticia/2008/05/12/310936/maestro-juan-pablo-izquierdo-encabeza-homenaje-izidor-handler-universidad-santa-maria.html [consulta 23/10/2013].

84 S/A 2008b "Juan Pablo Izquierdo dirigirá a la Orquesta de Cámara de Chile en el Teatro Oriente. Disponible en: http://www.latercera.com/contenido/29_32426_9.shtml [consulta 23/10/2013] .

85 S/A 2008c "Juan Pablo Izquierdo con la Orquesta de Cámara de Chile se presenta mañana en Las Condes", 3 de noviembre. En: http://www.latercera.com/contenido/29_69548_9.shtml [consulta 23/10/2013].

86 S/A. [2008] "Orquesta de Cámara de Chile llega al Aula Magna de la Universidad Santa María". Disponible en: http://noticias.universia.cl/vida-universitaria/noticia/2008/11/06/300297/orquestacamara-chile-llega-aula-magna-universidad-santa-maria.html [consulta 23/9/2013].

87 S/A 2009a: 89. 
en distintos escenarios. No se debe olvidar que el 25\% de la programación de la Orquesta de Cámara es de música nacional. Una selectiva muestra da cuenta de ello. En 2009, por ejemplo, en Santiago, la temporada de la Corporación Cultural de Las Condes, en el concierto realizado en la parroquia Santa Elena -24 de julioJuan Pablo Izquierdo junto a la Orquesta de Cámara de Chile ofreció el Movimiento concertante para saxofón alto y cuerdas op. 123, de Juan Orrego-Salas, con Miguel Villafruela en la parte solista. Esta obra fue programada también en la Temporada Sinfónica de la Corporación Cultural Universidad de Concepción, esta vez con la Orquesta Sinfónica de esa Universidad, bajo la dirección de Izquierdo. Por otra parte, con la Orquesta de Cámara de Chile, dirigió -el 15 de mayo- la Elegía (in memoriam Béla Bartók) de Cirilo Vila, en la Temporada de Conciertos de Nuñoa, realizada en el Teatro Municipal de dicha comuna ${ }^{88}$ y Samech de Juan Allende-Blin en la misma temporada y en la Temporada de Conciertos Las Condes el 18 de noviembre. Por otra parte, la presentación de la Orquesta de Cámara de Chile, bajo su dirección, en la comuna de La Granja el 19 de noviembre se incluyó Rincones sordos de Fernando García, composición que también formó parte del programa de dicha Orquesta en Valparaíso, en el concierto efectuado el 21 de noviembre en el Aula Magna de la Universidad Técnica Federico Santa María ${ }^{89}$.

En 2010 Juan Pablo Izquierdo obtuvo el Premio a la Música Nacional "Presidente de la República 2009", en la categoría Música Clásica, ocasión en la cual la mandataria Michelle Bachelet destacó su "gran trabajo por difundir en el mundo popular el repertorio sinfónico contemporáneo"90. En 2011 la Orquesta de Cámara de Chile obtuvo el premio del Círculo de Críticos de las Artes a la mejor temporada musical 2011. En 2012, como es sabido, su director titular recibió el Premio Nacional de Artes Musicales, "por el aporte al desarrollo musical nacional en el ámbito del repertorio orquestal y su estímulo a músicos de las nuevas generaciones en Chile y el extranjero ${ }^{91}$ ", como comentó un medio de prensa. Paralela y paulatinamente, Izquierdo junto a la Orquesta han ido conquistando espacios y alcanzando objetivos.

Como muestra de los logros del proyecto que Juan Pablo izquierdo anunciara al asumir como director titular de la Orquesta de Cámara de Chile, se puede señalar la gira efectuada a Argentina y Uruguay con debut en el Teatro Colón de Buenos Aires. Posteriormente, con la Orquesta realizó dos giras por Chiloé, ambas en 2011, otra por Coquimbo, Ovalle y Andacollo este año -2013- así como los conciertos en distintas comunas de Santiago y en provincias, incluyendo los educacionales. Durante 2012 la Orquesta de Cámara realizó más de 80 presentaciones, con una gira al norte y presentaciones en las regiones de Valparaíso, O’Higgins y Metropolitana ${ }^{92}$. La

88 S/A. 2009 b: 124.

89 S/A. 2010: 142, 144.

90 Disponible en : http://www.scd.cl/www/index.php/noticias/patricio-manns-chancho-enpiedra-y-juan-pablo-izquierdo-recibieron-el-premio-presidente-de-la-republica-2009/

91 Tres de septiembre, 2012 Disponible en: http://www.latercera.com/noticia/ cultura/2012/09/1453-481523-9-premio-nacional-de-musica-2012-recae-en-juan-pablo-izquierdo. shtml [consulta 2/10/2013].

92 Disponible en: http://www.cultura.gob.cl/patrimonio/orquesta-de-camara/ 
programación del presente año -2013- es nutrida y abarca el repertorio orquestal tradicional, obras contemporáneas y composiciones chilenas, sin olvidar los estrenos. Para este año se contemplan dos encargos efectuados a los compositores Carlos Zamora y Miguel Farías ${ }^{93}$. La dirección estará a cargo de Izquierdo y directores invitados. No menos relevante son los conciertos educacionales, cuyo principal objetivo es formar audiencias. En este sentido, cabe mencionar, a modo de ejemplo, el programa de conciertos gratuitos de la Orquesta de Cámara de Chile, coordinado por el Consejo Nacional de la Cultura y las Artes de la Región Metropolitana con la Fundación Beethoven, el que por segundo año consecutivo ofrece para colegios de educación básica y media ${ }^{94}$.

\section{PALABRAS FINALES}

Las páginas anteriores dan cuenta del vasto universo sonoro que maneja Juan Pablo Izquierdo. Si bien se advierten ciertas preferencias por compositores como Johann Sebastian Bach, Ludwig van Beethoven, Arnold Schönberg, Anton Webern o Gustav Mahler, entre otros, su apertura a nuevas músicas siempre está presente. Una muestra clara de ello es su preocupación por llevar al escenario el repertorio contemporáneo tanto chileno como extranjero. Si bien este rasgo implica una decisión personal, también se vincula a su idea de una proyección amplia de la música, que desestima la incapacidad del público de aceptación de un repertorio diferente al que está habituado ${ }^{95}$. Por el contrario, en su opinión, la audiencia nacional ${ }^{96}$ :

"Es un público ávido de escuchar cosas nuevas, interesantes. Los chilenos quieren oír y entender incluso piezas experimentales, lo he comprobado [...]. Es lo contrario de lo que dicen los organizadores: que siempre hay que tocar lo mismo, no salirse de lo clásico. Está probado que es un error. Le tengo mucha fe al público chileno, es culto y abierto. Y busca. Soy un convencido de que podemos hacer crecer mucho las audiencias y voy a trabajar por eso".

Lo anterior, desde mi óptica, revela una faceta docente o pedagógica, tema que en esta comunicación no alcanzamos a tratar y que Izquierdo ha desarrollado tempranamente en su carrera y desde diferentes perspectivas. Por ejemplo, implícitamente con sus propias programaciones, en el fructífero trabajo con jóvenes músicos en Pittsburgh, Estados Unidos ${ }^{97}$, y por medio de los frecuentes conciertos masivos y $(o)$ educacionales que ha realizado en Chile.

93 Romina de la Sotta, "El nuevo ritmo de Juan Pablo Izquierdo y la Orquesta de Cámara de Chile”, El Mercurio online, domingo 21 de abril de 2013. Disponible en: http://diario.elmercurio. com/detalle/index.asp?id=\% 7Bdc34f117-5cc3-4859-b0c0-2a82801b94a5\% 7D [consulta 24/10/2013].

94 Disponible en: http://www.cultura.gob.cl/convocatorias/consejo-de-la-cultura-rm-te-invita-aparticipar-de-conciertos-educacionales-gratuitos / [consulta 24/10/2013].

95 Warnken 2011.

96 Jurado 2010: 147.

97 Cf. el trabajo de Marilyn Taft Thomas, publicado en este número de la Revista. 
Otra característica significativa de su personalidad musical, que se advierte a la hora de elaborar programas es el criterio orgánico de planificación, atendiendo a continuidades y cambios, en términos de lenguaje. Se podría decir que hay una mirada a las obras en función o en relación con sus poéticas. Este rasgo está estrechamente relacionado con el proceso reflexivo sobre su propio oficio y con el modo en que trabaja con la música desde el momento de su estudio. Vale decir, se aproxima a la obra como si fuera la primera vez que la aborda, penetra en cada ocasión en su estructura interna y evita caer en la reproducción mecánica, para vulnerar, de este modo, la posibilidad de una interpretación "segura". Como señaló en una entrevista: "Después de tantos años, lo que me interesa hoy es entrar en la profundidad de una obra como la Sinfonía Heroica. Ese es el sentido que para mí tiene dirigir ${ }^{98}$ ".

Finalmente, dos comentarios. Por una parte, es importante recordar que el proyecto que actualmente Juan Pablo Izquierdo realiza junto a la Orquesta de Cámara de Chile está en pleno desarrollo, razón por la cual esta etapa de su actividad musical podrá ser evaluada integralmente más adelante. Sin embargo, cabe decir que la apuesta de incluir un 25\% de música chilena es un desafío (riesgo para otros) que no cualquier músico afronta. Por otra parte, sobre su quehacer no está todo dicho. Quedan pendientes la realización de estudios sobre su producción fonográfica, sus interpretaciones o su visión de la formación del músico ${ }^{99}$, entre otros temas que ameritan ser estudiados en el futuro.

\section{BIBLIOGRAFÍA}

Se divide en las siguientes partes: (1) fuentes impresas, (2) archivos, (3) periódicos y (4) sitios web. Sin perjuicio de las referencias a la dirección electrónica de Scielo para las entradas relativas a la Revista Musical Chilena, estas se pueden consultar además en www. revistamusicalchilena.uchile.cl.

\section{Fuentes impresas}

Bustos Valderrama, RaQuel

2007 “Leni Alexander Pollack (1924-2005)”, RMCh, LXI / 207 (enero-junio), pp. 28-64.

Cerda, Sebastián

2008 "Juan Pablo Izquierdo debuta al mando de la Orquesta de Cámara", El Mercurio online, miércoles 14 de mayo. Disponible en: http://www.emol.com/noticias/ magazine/2008/05/14/304321/juan-pablo-izquierdo-debuta-al-mando-de-laorquesta-de-camara.html [consulta 5/6/2013].

De la Sotta Donoso, Romina

2013 "El nuevo ritmo de Juan Pablo Izquierdo y la Orquesta de Cámara de Chile", El Mercurio online, domingo 21 de abril. Disponible en: http://diario.elmercurio. com/detalle/index.asp?id=\% 7Bdc34f117-5cc3-4859-b0c0-2a82801b94a5\%7D [consulta 24/10/2013].

98 Jurado 2010: 144.

99 Cf. Izquierdo 1994. 
Grebe Vicuña, María Ester

1967 "El Quinto Festival de Primavera de Música Latinoamericana de la Universidad de Indiana", RMCh, XXI/100 (abril-junio), pp. 107-108.

1968 "León Schidlowsky Gaete. Síntesis de su trayectoria creativa (1952-1968), RMCh, XXII/104-105 (abril-diciembre), pp. 7-52.

\section{Heinlein Funcke, Federico}

1967a "Noveno concierto sinfónico", El Mercurio, Santiago, domingo 9 de julio, p. 59.

1967b "Décimo concierto sinfónico", El Mercurio, Santiago, domingo 19 julio, p. 56.

1967c "Dos conciertos”, El Mercurio, Santiago, domingo 30 de julio, p. 63.

1968a “Ives, Schidlowsky, Mozart”, El Mercurio, Santiago, miércoles 10 de julio, p. 41.

1968b "Ballet y música”, El Mercurio, Santiago, martes 23 julio, p. 30.

1968c "Dos conjuntos nacionales”, El Mercurio domingo 28 julio, p. 55

1983a "Segundo programa de la Filarmónica", El Mercurio, jueves 14 de abril, p. C16.

1983b "Último programa de la Temporada Filarmónica”, El Mercurio, jueves 30 de junio, p. C11.

1983c “Búsquedas”, El Mercurio, Santiago, jueves 15 de diciembre, p.C10.

1984a "Noventa y siete minutos de goce”, El Mercurio, Santiago, sábado 24 de marzo, p. C19.

1984b “La Pasión según San Juan, de Bach”, El Mercurio, Santiago, lunes 16 de abril, p. C8.

1984c "Regreso a la Patria: bienvenido, Claudio Arrau”, El Mercurio, Santiago, lunes 14 de mayo, p. C10.

1984d “Grandioso monumento antibelicista”, El Mercurio, Santiago, sábado 14 de julio, p. C15.

1984e “Turangalila”, El Mercurio, Santiago, martes 27 de noviembre, p. C9.

1984f “Clausura de temporada en el Municipal”, El Mercurio, Santiago, viernes 21 de diciembre, p. C19.

1985a "El arte de la fuga, de Bach”, El Mercurio, Santiago, sábado 23 de marzo, p. C15.

1985b “Dos Sinfonías”, El Mercurio, Santiago, jueves 9 de mayo, p. C11.

1985c “La Sexta, de Mahler”, El Mercurio, Santiago, lunes 12 agosto, p. C11.

1985d "Duodécimo programa filarmónico”, El Mercurio, Santiago, lunes 26 de agosto, p. C9.

1985e “Obras del siglo XX”, El Mercurio, viernes 6 de diciembre, p. C14.

1986a "Programa austríaco”, El Mercurio, sábado 15 marzo, p. C14.

1986b “Segundo programa filarmónico”, El Mercurio, sábado 22 de marzo, p. C13.

1986c "Dos conciertos”, El Mercurio, viernes 6 de junio, p. C17.

1986d “Décimo programa filarmónico”, El Mercurio, lunes 17 noviembre, p. C9.

1986e “Requiem alemán”, El Mercurio, miércoles 17 de diciembre, p. C14. 
Herrera Ortega, Silvia

2003 "Eduardo Maturana: un compositor del siglo XX", RMCh, LVII/199 (enero-junio), pp. 7-38. Disponible en: http:/ / www.scielo.cl/scielo.php?pid=s071627902003019900001\&script=sci_arttext [consulta 25/10/2013].

IzQuierdo Fernández, Juan Pablo

1994 "Nivel de desarrollo profesional de los intérpretes chilenos" en Eduardo Carrasco y Mili Rodríguez (editores), Seminario sobre la situación de la música clásica en Chile. Santiago: [sin indicación de editor], pp. 129-134.

Jurado, María Cristina

2010 Creadores contra viento y marea. Santiago: Catalonia.

Merino Montero, Luis

1980 "Víctor Tevah, Premio Nacional de Arte en Música 1980", RMCh, XXXIV/152 (octubre-diciembre), pp. 5-22.

Orrego Salas, Juan

2003 "Exilio, ¿pérdida o provecho?”, RMCh, LVII/199 (enero-junio), pp. 66-69.

2005 Encuentro, visiones y reparos. Santiago: Ediciones Universidad Católica de Chile.

Parra Moreno, Waldo

2000 "Izquierdo Fernández, Juan Pablo". Diccionario de la Música Española e Hispanoamericana. Editado por Emilio Casares Rodicio. Tomo VI. Madrid: Sociedad General de Autores y Editores (SGAE), p. 515.

Peña Fuenzalida, Carmen

2007 "Fernando Rosas Pfingsthorn, Premio Nacional de Arte en Música 2006", $R M C h$, LXI (enero-junio), pp. 6-27.

Quintana, Sonia

1984 “'Turangalila' de Messiaen: un monumental canto al amor”, El Mercurio, domingo 25 de noviembre, p. E4.

Riesco Grez, Carlos

1963 “Octavo Festival de Música Chilena”, RMCh, XVII/ 83 (1963) (enero-marzo), pp. 7-36.

Salvo, Baccio

1966 "Juan Pablo Izquierdo", El Mercurio, [domingo] 6 febrero, [snp] (Recorte, Centro DAE Teatro Municipal).

$\mathrm{S} / \mathrm{A}$

1960 "Crónica. Conciertos de primavera de la Orquesta Sinfónica de Chile", RMCh, XIV/73 (septiembre-octubre), p. 119.

1961 a “Crónica. Orquesta Filarmónica de Chile”, RMCh, XV/76 (abril-junio), p. 80.

1961b “Crónica. Temporada lírica internacional 1961”, RMCh, XV/77 (julio-septiembre), p. 116.

1961c “Crónica. Ópera. Estreno de 'La sugestión' ”, RMCh, XVI/ 78 (octubre-diciembre), pp. 88-89.

1962 "Crónica. Conciertos en la Universidad Católica”, RMCh, XVI/ 81-82 (juliodiciembre), pp. 211-212. 
1963a "Crónica. Departamento de Música de la Universidad Católica de Chile", RMCh, XVII/83 (enero-marzo), p. 127.

1963b “Crónica. Orquesta Sinfónica de Chile”, RMCh, XVII/84 (abril-junio), p. 91.

1963c “Crónica. Orquesta Sinfónica de Chile”, RMCh, XVII/ 85 (julio-septiembre), p. 101.

1963d “Crónica. "Estreno de 'Dido y Eneas', de Henry Purcell”, RMCh, XVII/ 85 (julioseptiembre), p. 109.

1964a “Crónica. Música en el norte y sur del país”, RMCh, XVIII/89 (julio-septiembre, pp. 158-159.

1964b “Crónica. XXIII Temporada de la Orquesta Sinfónica de Chile”, $R M C h$, XVIII/89 (julio-septiembre), p. 138.

1964c "Crónica. XXIII Temporada de la Orquesta Sinfónica de Chile”, RMCh, XVIII /90 (octubre-diciembre), pp. 82-83.

1965a "Crónica. Orquesta Sinfónica de Chile, actuaciones en 1964 y conciertos al aire libre en enero de1965”, RMCh, XIX/91 (enero-marzo), p. 66.

1965b “Crónica. Ballet”, RMCh, XIX/92 (abril-junio), pp. 96-98.

1965c "Crónica. XXIV Temporada de Invierno de la Orquesta Sinfónica de Chile", $R M C h$, XIX/ 93 (julio-septiembre), pp. 98-99.

1966a "Crónica. XXV Temporada Oficial de la Orquesta Sinfónica de Chile", $R M C h, \mathrm{XX} / 97$ (julio-septiembre), pp. 69-70.

1966b “Crónica. XII Temporada de la Orquesta Filarmónica Municipal”, RMCh, XX/97 (abril-junio), pp. 77-81.

1966c “Crónica. Concepción. XV Temporada Oficial”, RMCh, XX/97 (abril-junio), p. 93.

1967 "Crónica. Juan Pablo Izquierdo dirige a la Filarmónica de Nueva York", $R M C h, \mathrm{XXI} / 100$ (abril-junio), pp. 93-94.

1971a “Crónica. Conciertos del Instituto de Extensión Musical”, RMCh, XXV/115-116 (julio-diciembre), pp. 71-73.

1971b "Crónica. Noticiario nacional. Éxitos internacionales del director de orquesta Juan Pablo Izquierdo", RMCh, XXV/115-116 (julio-diciembre), pp. 89-90.

1972 "Crónica. Festival de Música Contemporánea en la Universidad Católica de Chile", $R M C h, \mathrm{XXVI} / 117$ (enero-marzo), pp. 86-87.

1980 "Recuento de la temporada de conciertos 1980", El Mercurio, Santiago, 23 noviembre, pp. E4-E5. Recorte en Centro DAE.

1981 “Gran temporada para los 125 años del Teatro Municipal”, El Mercurio, Santiago, domingo 8 de noviembre, p. E13.

1983a "Filarmónica conquistó ovación del público". El Mercurio, Santiago, jueves 14 de abril, p. C16.

1983b “El sábado: se inicia I Festival de Música Contemporánea”, El Mercurio, Santiago, jueves 1 de diciembre, p. C12. 
1983c "Obras de Riffo [sic.] y Guarello estrena la Filarmónica”, El Mercurio, Santiago, sábado 3 diciembre, p. C12.

1984a “Juan Pablo Izquierdo no dirigirá 'Elektra”, El Mercurio, Santiago, viernes 7 de septiembre, p. C12.

1984b "Juan Pablo Izquierdo dirigirá ópera contemporánea en Holanda”, El Mercurio, Santiago, martes 6 de noviembre, p. C12.

1984c "Semana musical: termina Festival de Música Contemporánea”, El Mercurio, Santiago, martes 18 noviembre, p. C15.

1985 "Juan Pablo Izquierdo: 'Quedé muy contento con el ajuste de la Orquesta al Teatro Astor'”, El Mercurio, Santiago, miércoles 13 de marzo, p. C11.

1986a "Domingo Santa Cruz elogió a la Filarmónica", El Mercurio, Santiago, sábado 22 de marzo, p. C13.

1986b “Juan Pablo Izquierdo: 'Tomamos la $5^{\text {a }}$ Sinfonía como por primera vez”, $E l$ Mercurio, Santiago, miércoles 5 de noviembre, p. C13.

1999a “Crónica. Otras noticias. Distinciones a músicos chilenos”, RMCh, LIII/ 191 (enero-junio), p. 103. Disponible en http://dx.doi.org/10.4067/S071627901999019100009 [consulta 30/9/2013].

1999b "Crónica. Creación musical chilena. Compositores chilenos en el país. Universidad de Chile, Teatro de la Universidad de Chile", RMCh, LIII/ 192 (1999) (juliodiciembre), p. 97.

2000 "Crónica. Creación musical chilena: compositores chilenos en el país", $R M C h, \mathrm{LIV} / 194$ (julio-diciembre), p. 105.

2006 “Crónica. Otras noticias”, RMCh, LX/205 (enero-junio), p. 100.

2008a "Maestro Juan Pablo Izquierdo encabeza homenaje a Isidor Handler en Universidad Santa María", 12 de mayo. Disponible en: http://noticias.universia. cl/vida-universitaria/noticia/2008/05/12/310936/maestro-juan-pablo-izquierdo-encabeza-homenaje-izidor-handler-universidad-santa-maria.html [consulta $23 / 10 / 2013]$.

2008b "Juan Pablo Izquierdo dirigirá a la Orquesta de Cámara de Chile en el Teatro Oriente, La Tercera, Santiago, 21 de julio. En: http://www.latercera.com/contenido/29_32426_9.shtml [consulta 23/9/2013].

2008c "Juan Pablo Izquierdo con la Orquesta de Cámara de Chile se presenta mañana en Las Condes", La Tercera, Santiago, 3 de noviembre. Disponible en: http:/ / www. latercera.com/contenido/29_69548_9.shtml [consulta 23/10/2013].

[2008] "Orquesta de Cámara de Chile llega al Aula Magna de la Universidad Santa María". En: http://noticias.universia.cl/vida-universitaria/noticia/2008/11/06/300297/ orquesta-camara-chile-llega-aula-magna-universidad-santa-maria.html [consulta 23/9/2013].

2009a "Crónica. Creación musical chilena: compositores Chilenos en el país", RMCh, LXIII/211 (enero-junio), p. 89.

2009b "Crónica. Creación musical chilena: compositores chilenos en el país" RMCh, LXIII/212 (julio-diciembre), p. 124. 
2010 “Crónica”, RMCh, LXIV/ 213 (enero-junio), pp. 142 у 144.

2013 "Juan Pablo Izquierdo vuelve a ponerse al mando de la Sinfónica en didáctico concierto", emol, jueves 18 de julio. http://www.emol.com/noticias/magazine/2013/07/18/609713/juan-pablo-izquierdo-se-pone-al-mando-de-la-sinfonica. html [consulta 23/10/2013].

Torres Alvarado, Rodrigo

2005 "Catálogo de las obras musicales de Cirilo Vila Castro", RMCh, LIX/203 (enerojunio), pp. 18-24.

Torres Alvarado, Rodrigo, José Quezada Machiavello y Aurelio Tello

2001 "Catálogo de las obras musicales de Celso Garrido-Lecca", RMCh, LV/196 (juliodiciembre), pp. 27-32 . Disponible en http://www.revistamusicalchilena.uchile. $\mathrm{cl} /$ index.php/RMCH/article/viewArticle/12556/12863 [consulta 14/9/2013].

VÉJAR, Francisco

2001 "Viaje al centro del sonido: conversación con Juan Pablo Izquierdo", Babab, $\mathrm{N}^{\circ}$ 9 (julio). Disponible en http://www.babab.com/no09/juanp_izquierdo.htm [consulta 30/04/2013].

Warnken, Cristián

2002 "Juan Pablo Izquierdo (2002): El oficio de director" . Disponible en http:/ /www. otrocanal.cl/video/juan-pablo-izquierdo-2002-el-oficio-de-director [consulta $18 / 6 / 2013)$.

2011 "Juan Pablo Izquierdo (2011). En el principio era el sonido". Disponible en http:/ / www.otrocanal.cl/video/juan-pablo-izquierdo-2011-en-el-principio-era-el-sonido [consulta 25/6/2013].

\section{Archivos}

Biblioteca Nacional de Santiago

Programas de concierto.

Prensa

Centro de Documentación de las Artes Escénicas (Centro DAE), Teatro Municipal De Santiago.

Programas de concierto de las temporadas de la Orquesta Filarmónica de Santiago 1983, 1984, 1986.

Recortes de prensa.

\section{Periódicos}

El Mercurio, Santiago

La Tercera, Santiago

4. Sitios web

http://centrodae.cl./ [consulta 3/9/2013]. 
http://www.scd.cl/www/index.php/noticias/patricio-manns-chancho-en-piedra-y-juanpablo-izquierdo-recibieron-el-premio-presidente-de-la-republica-2009/ [consulta 6/10/2013].

[La Tercera], 3/9/2012 http://www.latercera.com/noticia/cultura/2012/09/1453481523-9-premio-nacional-de-musica-2012-recae-en-juan-pablo-izquierdo.shtml [consulta 2/10/2013].

http://www.cultura.gob.cl/patrimonio/orquesta-de-camara/ [consulta 9/10/2013].

http:/ / www.cultura.gob.cl/convocatorias/consejo-de-la-cultura-rm-te-invita-a-participar-deconciertos-educacionales-gratuitos/ [consulta 24/10/2013].

http://www.aliciadelarrocha.com/international-pianist/node/24910 [consulta $25 / 11 / 2013]$. 